\title{
Schwann cell p75 neurotrophin receptor modulates small fiber degeneration in diabetic neuropathy
}

Running title: Schwann cell p75 in diabetic neuropathy

\author{
Nádia Pereira Gonçalves ${ }^{1,2, *}$, Sara Elgaard Jager ${ }^{1,3}$, Mette Richner ${ }^{1}$, Simon Murray4, Simin \\ Mohseni $^{5}$, Troels Staehelin Jensen ${ }^{2,6}$, Christian Bjerggaard Vægter ${ }^{1,2}$
}

1) Danish Research Institute of Translational Neuroscience - DANDRITE, Nordic-EMBL Partnership for Molecular Medicine, Department of Biomedicine, Aarhus University, 8000 Aarhus C, Denmark

2) International Diabetic Neuropathy Consortium (IDNC), Aarhus University Hospital, 8200 Aarhus N, Denmark

3) Wolfson Centre for Age-Related Diseases, King's College London, London, UK

4) Department of Anatomy and Neuroscience, The University of Melbourne, Victoria, Australia

5) Department of Biomedical and Clinical Sciences, Linköping University, Linköping, Sweden

6) Department of Neurology and Danish Pain Research Center, Aarhus University, DK- 8000 Aarhus C, Denmark

*Corresponding author: Nádia Pereira Gonçalves, npg@dandrite.au.dk

\section{Acknowledgements}

We are thankful to Professor Eva Feldman and John Hayes, University of Michigan, and Maria Ntzouni, Linköping University, for the provided training on nerve conduction velocity and sample processing for TEM, respectively. We thank Daphne Nabben, Marianne Kristensen and Marie Sjøgaard, from Aarhus University, for the technical assistance with the g-ratio analysis and tissue cryosectioning. We also thank Dr. Jane Hvarregaard Christensen, Aarhus University, for the critical discussions regarding preparation of tissue for RNA sequencing.

The authors are supported by Aarhus University Research Foundation (AUFF-E-2015-FLS-8-4), Independent Research Fund Denmark (8020-00118B), a challenge grant from the Novo Nordisk Foundation (NNF14OC0011633) and Dagmar Marshals Fond.

This is the author manuscript accepted for publication and has undergone full peer review but has not been through the copyediting, typesetting, pagination and proofreading process, which may lead to differences between this version and the Version of Record. Please cite this article as doi: 10.1002/glia.23881

This article is protected by copyright. All rights reserved. 
Word count: 10930 in total. Abstract: 226; Introduction: 925: M\&M: 1660; Results: 1562; Discussion: 1954; References: 2884; Figure legends:1418.

\begin{abstract}
Diabetic neuropathy has an incidence as high as $50 \%$ of diabetic patients and is characterized by damage to neurons, Schwann cells and blood vessels within the peripheral nervous system. The lowaffinity neurotrophin receptor p75 ( $75^{\mathrm{NTR}}$ ), particularly expressed by the Schwann cells in the peripheral nerve, has previously been reported to play a role in developmental myelination and cell survival/death. Increased levels of $\mathrm{p} 75^{\mathrm{NTR}}$, in the endoneurium and plasma from diabetic patients and rodent models of disease, have been observed, proposing that this receptor might be involved in the pathogenesis of diabetic neuropathy. Therefore, in this study, we addressed this hypothesis by utilizing a mouse model of selective nerve growth factor receptor ( $N g f r$ ) deletion in Schwann cells (SC-p75 $\left.{ }^{\mathrm{NTR}}-\mathrm{KO}\right)$. Electron microscopy of sciatic nerves from mice with high fat diet induced obesity demonstrated how loss of Schwann cell-p $75^{\text {NTR }}$ aggravated axonal atrophy and loss of C-fibers. RNA sequencing disclosed several pre-clinical signaling alterations in the diabetic peripheral nerves, dependent on Schwann cell p75 ${ }^{\mathrm{NTR}}$ signaling, specially related with lysosome, phagosome and immune pathways. Morphological and biochemical analyses identified abundant lysosomes and autophagosomes in the C-fiber axoplasm of the diabetic SC-p $75^{\mathrm{NTR}}-\mathrm{KO}$ nerves, which together with increased Cathepsin B protein levels corroborates gene upregulation from the phagolysosomal pathways. Altogether, this study demonstrates that Schwann cell p $75^{\mathrm{NTR}}$ deficiency amplifies diabetic neuropathy disease by triggering overactivation of immune-related pathways and increased lysosomal stress.
\end{abstract}

Keywords: C-fibers, diabetic neuropathy, immune response, lysosomes, p75 ${ }^{\mathrm{NTR}}$, Schwann cells.

This article is protected by copyright. All rights reserved. 


\section{Main points}

- HFD induces obesity, mechanical allodynia and reduction of NCV in a similar fashion in WT and SC-p $75^{\mathrm{NTR}}-\mathrm{KO}$ mice

- Loss of Schwann cell $p 75^{\mathrm{NTR}}$ accelerates C-fiber degeneration in diabetic neuropathy and modulates lysosomal and immune-related pathways

\section{Table of Contents Image}

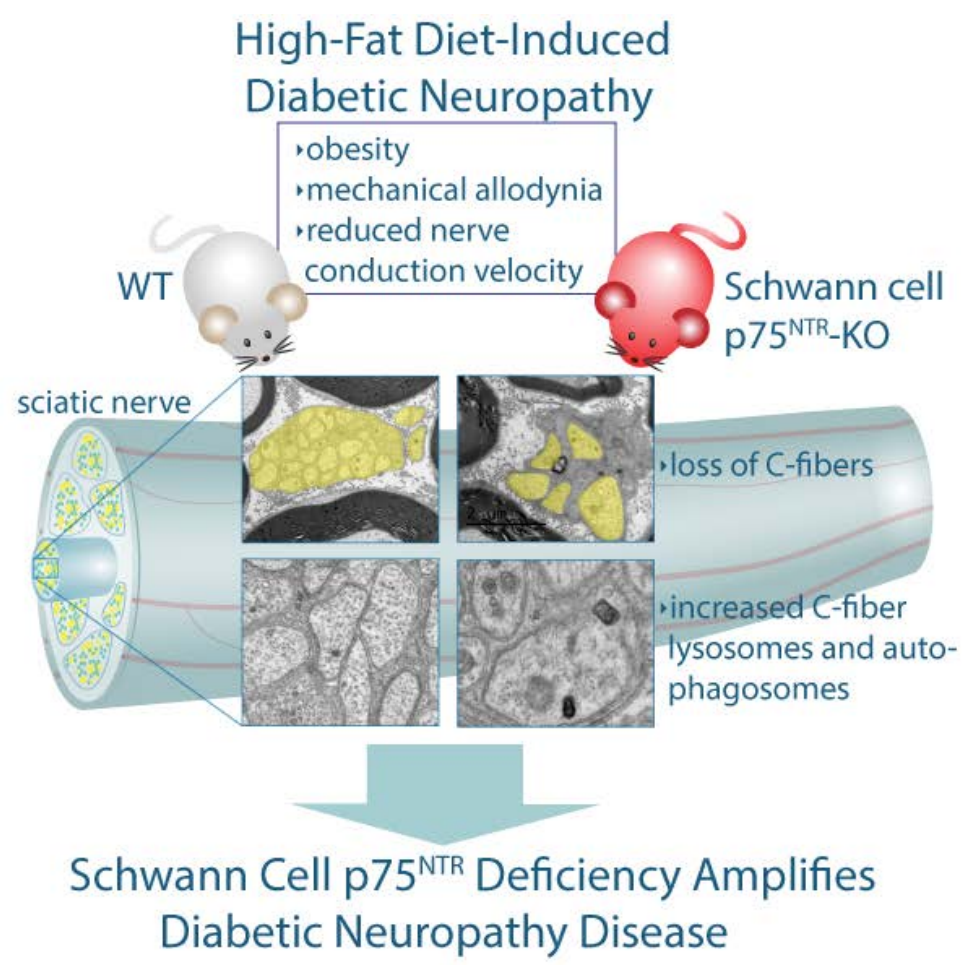

This article is protected by copyright. All rights reserved. 


\section{Introduction}

The International Diabetes Federation estimates that 1 in 11 adults currently suffers from diabetes, corresponding to 425 million people worldwide; a number that is expected to rise to 700 million by 2045 (edition, 2015). This development reflects an increase in associated risk factors, such as obesity, and an escalation of patients with diabetic complications; ranking diabetes as the biggest global disease outbreak of the $21^{\text {st }}$ century. Peripheral neuropathy is by far the most prevalent complication of diabetes, affecting up to $50 \%$ of diabetic patients and representing the leading cause for non-traumatic lower limb amputations (Boyko et al., 2018). Typical diabetic neuropathy is characterized by initial damage to the distal longest small caliber sensory axons innervating the skin, later on expanding proximally, and thus being considered pathologically as a length-dependent axonopathy with a "stocking and glove" pattern (Feldman et al., 2019). The condition is associated with significant morbidity, with patients presenting pain, numbness, tingling and ultimately muscle weakness as some of the classical clinical symptoms.

Primary pathogenic culprits contributing to diabetic neuropathy include hyperglycemia and dyslipidemia (Grisold et al., 2017), promoting the glycation of numerous structural and functional proteins to form advanced glycation end-products (AGEs) that modify gene expression towards a pro-inflammatory state by binding to the AGE receptor (RAGE) (Gonçalves et al., 2017). RAGE signaling contributes to increased glucose metabolism via the polyol and hexosamine pathways, resulting in the generation of reactive oxygen species, mitochondrial dysfunction and reduced nerve blood flow, overall leading to sensory neuron degeneration, axon loss and demyelination (Feldman et al., 2017; Richner et al., 2018). However, whether damage first targets peripheral axons or their supportive Schwann cells still remains unclear. Glial cells require relatively low energy under normal conditions as they derive sufficient ATP from glycolysis and supply excess pyruvate to

This article is protected by copyright. All rights reserved. 
axons (Halim et al., 2010). Schwann cells might not, therefore, be well adapted to metabolize excess glucose, suggesting that diabetic axonopathy may reflect other primary pathogenic insults such as loss of Schwann cell support.

Schwann cells are the most abundant cells of the peripheral nervous system (PNS), ensheathing all axons of peripheral nerves as either myelinating or unmyelinating cells (Jessen and Mirsky, 2005). Upon nerve damage, Schwann cells are able to dedifferentiate, reverting their phenotype towards an immature state, crucial for their proliferation, migration and guidance of neuronal regeneration and remyelination (Gaudet et al., 2011). Schwann cells have a fundamental role in regulating the molecular organization of the axoplasm, including the axonal microtubular content, nodal architecture and axon trafficking parameters (Court and Alvarez, 2016; Pan and Chan, 2017). Additionally, a body of evidence is now contrasting the idea that all axonal proteins are specified by the neuronal soma at the dorsal root ganglia (DRG), a process that would be extremely challenging for sensory neurons whose axons extend up to more than one meter in humans. In this context, it is now accepted that neurons also synthesize proteins locally in axons and dendrites, and that this process may be assisted by Schwann cells supplying axons with miRNA by way of exosomes (Court et al., 2008; Jung et al., 2012; Lopez-Verrilli et al., 2013). Thus, Schwann cell damage or malfunction triggered by toxic molecular events secondary to hyperglycemia and dyslipidemia might ultimately lead to dysfunctions of the Schwann cell-axon transport unit and compromise the axon-glia functional syncytium (Mizisin, 2014).

Diabetic Schwann cell failure results in myelin disruption, demyelination, changes in axonal conduction and compromised production of neurotrophic factors (Dey et al., 2013; Dunnigan et al., 2013; Gonçalves et al., 2017). Critical roles for PNS development and repair are mediated by the neurotrophins, involved in axonal sprouting and survival, Schwann cell migration and myelination. Neurotrophin action depends on their binding to distinct classes of receptors: the Trk tyrosine kinase receptors (TrkA, B, and C) or the p75 neurotrophin receptor ( $75^{\mathrm{NTR}}$ ), a member of the tumor necrosis factor superfamily (Chao, 2003). In the PNS, p75 ${ }^{\text {NTR }}$ is expressed both by subtypes of sensory neurons and Schwann cells and may mediate cell survival or cell death, promote or inhibit axonal growth and facilitate or attenuate proliferation, all depending on the cellular context and on binding of coreceptors (Cragnolini and Friedman, 2008). With respect to diabetic neuropathy, elevated p $75^{\mathrm{NTR}}$ protein levels were observed in myelin sheaths surrounding fibers undergoing axonal degeneration, suggesting a potential role for this receptor in axonopathy (Scarpini et al., 1996). Supporting this idea, a study with streptozotocin-induced diabetes in rats found that increased levels of plasma p $75^{\text {NTR }}$ may serve as an early indicator of neuronal dysfunction or damage in diabetic neuropathy (Chilton et al., 2004). A recent study indicates how miRNA composition of Schwann cell-derived exosomes changes upon high-glucose stimulation in vitro (Jia et al., 2018), which together with the presence of p75 ${ }^{\mathrm{NTR}}$ in Schwann cell secreted exosomes (Lopez-Verrilli et al., 2013) further suggests a role of Schwann cell p75 ${ }^{\text {NTR }}$ in axonal regulation. Finally, these observations together with the well-characterized upregulation of $7^{\mathrm{NTR}}$ in reprogramming Schwann cells in response to nerve damage (Jessen and Arthur-Farraj, 2019) and its role in regulating nerve conduction velocity (Gonçalves et al., 2019), lead us to hypothesize that Schwann cell $p 75^{\mathrm{NTR}}$ might play a similar critical role in diabetes-induced 
peripheral nerve damage. Therefore, here, we have investigated the effects of Schwann cell nerve growth factor receptor ( $N g f r$ ) expression on the development and progression of diabetic neuropathy. We used in vivo analysis by modeling type 2 diabetes in mice with a high fat diet (HFD), and so avoiding a line based on mutations or genetic manipulations of the leptin signaling system to better resemble the clinical setting.

This article is protected by copyright. All rights reserved. 


\section{Materials and Methods}

\section{Conditional Schwann cell p75 ${ }^{\mathrm{NTR}}$ null mouse model generation}

Conditional Schwann cell p75 ${ }^{\text {NTR }}$ knockout (KO) mice (referred to as SC-p75 ${ }^{\text {NTR }}$-KO throughout the manuscript) were obtained by crossing transgenic mice containing the myelin protein zero (MPZ) promoter driving expression of Cre recombinase (Mpz-cre) (sourced from the Jackson Laboratory strain \#017927) (Feltri et al., 1999) with a p75 ${ }^{\mathrm{fl} / f l}$ (Boskovic et al., 2014). Upon recombination, p75 ${ }^{\mathrm{NTR}}$ genomic DNA flanked by the loxP sites in Schwann cells is inverted and replaced by mCherry expression (Boskovic et al., 2014; Gonçalves et al., 2019). All mice were housed under specific pathogen-free conditions and animal protocols were carried out in accordance with the European Community Council Directive (2010/63/EU) and approved by The Danish Animal Experiments Inspectorate (2017-15-0201-01192 C2).

\section{Modeling type 2 diabetic neuropathy}

Male SC-p75 ${ }^{\text {NTR }}$-KO mice, in the C57BL/6 background, together with male wild-type (WT) littermates were feed either with a standard diet, consisting of $10 \%$ kcal from fat (Research Diets Inc.; \#D12450B, New Brunswick, NJ, USA), or a high fat diet (HFD) with 60\% kcal fat from lard (Research Diets Inc.; \#D12492) from 5 weeks of age. A total number of $n=10$ mice were used per treatment group.

Mice were cared for in a temperature-controlled pathogen-free environment, under a $12 \mathrm{~h}$ light/dark cycle, with water and food ad libitum. Body weights were registered once a month during the entire experimental timeline and animals were euthanized with isoflurane, after 24 weeks with the special feeding.

\section{Behavioral Tests}

Von Frey test: Unrestrained mice were acclimatized in a Plexiglas cage atop a wire mesh grid for approximately 15 min prior to testing. Mechanical withdrawal thresholds were assessed by manually applying calibrated Semmes-Weinstein monofilaments (Stoelting Co) onto the midplantar surface of the hind paws using the 'ascending stimulus' method (Dixon, 1980). The stimulus was repeated 5 times with each filament and a positive response in at least three out of five stimuli determined the withdrawal threshold (expressed in grams). The average of both paws per mouse was used for statistical analysis.

Hargreaves test: Thermal pain thresholds in the hind paws of mice was evaluated with the Hargreaves method using an infrared light heat stimulus (radiant heat source at 50\%; $190 \mathrm{~mW} / \mathrm{cm} 2$; Ugo Basile, Italy) (Hargreaves et al., 1988). Unrestrained animals were let to acclimatize in acrylic cubicles placed upon a glass surface for $1 \mathrm{~h}$ before the procedure. Three responses were recorded for each hind paw which were tested alternately with 5 minutes between consecutive measurements. A cut-off of 20 sec stimulus latency was established to avoid potential tissue damage. 


\section{Electrophysiology}

Sural sensory and sciatic motor nerve conduction velocities (NCV) were performed under 2\% isoflurane anesthesia, using a Viking Quest apparatus (Natus Neurology Incorporated, United States) (Hinder et al., 2017). Briefly, for recording sural NCV, stainless steel needle electrodes (Natus Biomedical, Madison, WI) were placed in the dorsum of the hind paw with supramaximal stimulation at the ankle and the velocity was calculated by dividing the distance between the recording and stimulating electrodes ( $\mathrm{mm}$ ) by the take-off latency (ms) of the sensory nerve action potential. For sciatic-tibial motor NCV, orthodromic stimulation was applied at the ankle, followed by the sciatic notch, and recorded at the dorsum of the paw. The distance between the two sites of stimulation was divided by the difference between the two onset latencies of the action potentials (ankle distance and notch distance) for a final motor $\mathrm{NCV}(\mathrm{m} / \mathrm{s})$. After the electrophysiological testing, mice were terminally anaesthetized with an overdose of isoflurane.

\section{Transmission Electron Microscopy (TEM) and Morphometric analysis}

Sciatic nerve samples ( $\mathrm{n}=4 / 5$ per group) were fixed in $2.5 \%$ glutaraldehyde in $0.1 \mathrm{M}$ phosphate buffer, $\mathrm{pH} 7.4$, washed in the same buffer, post fixed in $2 \%$ osmium tetroxide for $1 \mathrm{~h}$ and stained with $2 \%$ uranyl acetate in $50 \%$ ethanol. Samples were then dehydrated in a series of ascending concentrations of ethanol and $100 \%$ acetone. A three-step infiltration in a mixture of acetone embedding medium (1:3, 1:1, 3:1) was performed prior to embedding (48 h at $60{ }^{\circ} \mathrm{C}$ ) in Epoxy Embedding Medium Kit (Sigma-Aldrich, Sweden AB). The blocks were initially trimmed and sectioned using a Leica UC7 ultra microtome (Leica Microsystems GmbH, Vienna, Austria). Ultrathin sections (60-nm thickness) were collected onto formvar-coated copper slot grids and counter stained with uranyl acetate and lead citrate. Images were taken using a 100kV transmission electron microscope (JEM 1230, JEOL Ltd., Tokyo, Japan). For each nerve, a panorama picture was created (x1000) for orientation and all myelinated fibers were counted, with results normalized to the respective nerve area for obtaining myelinated nerve fiber density. Light microscopic pictures of myelinated fibers were uploaded on Image $\mathrm{J}$ software and the axon and fiber size of 150 myelinated fibers per animal were determined and averaged for calculating the g-ratio. Axon-free myelin fragments and fibers undergoing demyelination were counted, with numbers normalized to the respective nerve area and depicted as density $\left(\mathrm{n} / \mathrm{mm}^{2}\right)$.

For C-fiber counting, 30 non-overlapping photographs (x15,000 amplification) per sciatic nerve were randomly acquired by starting the analysis at one corner of the fascicle and photographing images of every third microscopic field. C-fibers, macrophages and bundles of flat sheets of Schwann cell cytoplasmic processes in the images were counted and their density calculated, normalizing to the area of each ultrathin section. Number of autophagic structures (lysosomes and autophagosomes) in c-fibers and in Schwann cell cytoplasmic processes in a unit with common basement membrane were counted, and the data was normalized against total number of c-fibers or bundle of cytoplasmic processes, respectively.

\section{RNA sequencing}


RNA sequencing was performed with BGI-Research, Shenzhen, China. Briefly, total RNA was isolated using the Lipid Tissue Mini Kit (Qiagen) from $n=5$ mice per treatment group. Magnetic beads with Oligo(dT) were then used to purify mRNA that was subsequently fragmented into small pieces. Complement first-strand DNA was generated using random hexamer-primed reverse transcription, followed by a second-strand cDNA synthesis. Synthesized cDNA was subjected to end reparation and single nucleotide A (adenine) addition. Adapters were next ligated to the ends of these 3' adenylated cDNA fragments. The suitable fragments were selected for PCR amplification and products purified with Ampure XP Beads (AGENCOURT) and dissolved in EB buffer. Library was validated on the Agilent Technologies 2100 Bioanalyzer. The double stranded PCR products were heat denatured and circularized by the splint oligo sequence. The single strand circle DNA (ssCir DNA) were formatted as the final library that was then amplified with phi29 to make DNA nanoball (DNB) which had more than 300 copies of one molecular. The DNBs were loaded into the patterned nanoarray and single end 50 bases reads were generated.

Following sequencing, the generated reads were filtered to remove adaptor sequences and low-quality reads. The clean reads were aligned to the reference genome with Bowtie2 (Langmead et al., 2009) using the following parameters -q --phred64 --sensitive --dpad 0 -gbar and HISAT (Kim et al., 2015) using the following parameters -p 8 --phred64 --sensitive -I 1 -X 1000. The gene expression was calculated as fragments per kilobase of exon per million fragments mapped (FPKM). The FPKM values were used as input for the NOISeq method (Tarazona et al., 2011) to calculate log2(foldchange) and determine differently expressed genes (DEGs). The final list of DEGs include genes with fold change $\geq 2$ and diverge probability $\geq 0.8$ as described in the NOIseq method. A probability of 0.8 means that the gene is 4 times more likely to be differentially expressed than non-differentially expressed. The list of DEGs were imported to STRING (Szklarczyk et al., 2017) in cytoscape (Shannon et al., 2003) to produce the networks and perform the enrichment analysis.

\section{Immunofluorescence microscopy}

Sciatic nerves and L4 DRGs ( $n=5$ per group) were post fixed in $4 \%$ paraformaldehyde for approximately $2 \mathrm{~h}$ and then transferred to $20 \%$ sucrose overnight at $4{ }^{\circ} \mathrm{C}$ for cryoprotection. Tissue was then embedded in Tissue-Tek (Sakura), snap frozen in isopentane on dry ice for storage at $-80^{\circ} \mathrm{C}$ until cryosectionning. Longitudinal nerve sections were cut at $5 \mu \mathrm{m}$ and DRG sections were cut at 10 $\mu \mathrm{m}$.

After drying, tissue sections were washed with phosphate buffer saline (PBS) and incubated in citrate buffer for $15 \mathrm{~min}$ at $80^{\circ} \mathrm{C}$ for antigen retrieval. Slides were then blocked with a buffer containing $10 \%$ fetal bovine serum in $0.3 \%$ Triton X-100 in PBS for $1 \mathrm{~h}$ at room temperature, followed by overnight incubation with the primary antibodies against Cathepsin b (Ctsb; 1:100, Cell Signaling) and $\beta$ III-tubulin (1:1000, Promega) at $4^{\circ} \mathrm{C}$. After proper rinsing with PBS, the sections were incubated for $2 \mathrm{~h}$ at room temperature with Alexa Fluor 488 anti-rabbit (Molecular Probes, 1:500), Alexa Fluor 568 anti-mouse (Molecular Probes, 1:500) and Hoechst (1:5000) for labelling of the nuclei. Slides were coverslipped with DAKO mounting medium and Z-stacked images captured by confocal microscopy (LSM780, Carl Zeiss, Germany). 


\section{Western blotting}

Lumbar DRGs (L3-L5) were lysed with a buffer containing $2 \mathrm{mM} \mathrm{CaCl}, 1 \mathrm{mM} \mathrm{MgCl}, 10 \mathrm{mM}$ HEPES, $140 \mathrm{mM} \mathrm{NaCl}$ and 1\% Triton X-100, $\mathrm{pH}$ 7.8, with protease inhibitors from Roche. After a 20 min centrifugation at $10.000 \mathrm{~g}$, the supernatant was used to determine the protein concentration using the Bicinchoninic Acid protein assay kit (Sigma). Thirty $\mu$ g of protein were mixed with SDS gel sample buffer and proteins electrophoresed on 12\% SDS-polyacrylamide gels blotted onto a nitrocellulose membrane and probed with antibodies against p $75^{\mathrm{NTR}}$ (1:500, Promega), Ctsb (1:1000, Cell Signaling) and $\beta$-actin (1:5000, Sigma). Secondary IgG horseradish peroxidase linked antibodies used were swine anti-rabbit (1:1000, Dako) and rabbit anti-mouse (1:1000, Dako). ECL prime Western blotting detection system (GE Healthcare) was used to visualize the immunoreactive bands by chemiluminescence, that were developed on a Fuji film LAS1000 X Ray Imager. Quantitative densitometric analysis of the relative protein levels were carried out with ImageJ software.

\section{Statistical analysis}

Data are expressed as mean \pm SEM. Statistical significance was determined using the two-tailed Student's t-test or Two-way ANOVA, followed by the Tukey's post hoc test, with Graph Pad Prism software, when two or multiple groups/time points were compared, respectively. Significance was established at $\mathrm{p}^{*}<0.05, \mathrm{p}^{* *}<0.01, \mathrm{p}^{* * *}<0.001$.

This article is protected by copyright. All rights reserved. 


\section{Results}

\section{Metabolic and neuropathy phenotyping of the SC-p75 ${ }^{\mathrm{NTR}}-\mathrm{KO}$ mice under HFD}

To study the involvement of Schwann cell p75 ${ }^{\mathrm{NTR}}$ expression in vivo in the context of diabetic neuropathy development and progression, we utilized a conditional p $75^{\mathrm{NTR}}$ Schwann cell KO model (SC-p75 ${ }^{\mathrm{NTR}}-\mathrm{KO}$ ), obtained by crossing and MPZ-Cre with a p75 ${ }^{\mathrm{fl} / \mathrm{fl}}$ (Figure 1a), previously characterized (Gonçalves et al., 2019). The HFD-stimulated obesity model of prediabetes is a wellestablished paradigm for inducing type 2 diabetic neuropathy as early as 16 weeks after initiation of special feeding (O'Brien et al., 2018; Rumora et al., 2019). In the present work, metabolic phenotyping was performed by measuring longitudinal changes in body mass over time while peripheral neuropathy was assessed only at the endpoint (24 weeks after the special feeding; Figure 1a). Between 8 and 24 weeks, both SC-p75 ${ }^{\mathrm{NTR}}$-KO and WT HFD-fed mice were significantly heavier than mice receiving a standard diet (Figure 1b). Assessment of neuropathy phenotype was made in accordance with the Animal Models of Diabetic Complications Consortium guidelines (Biessels et al., 2014), specifically by measuring hind paw withdrawal latencies, and sural sensory and sciatic motor NCV. Both SC-p75 ${ }^{\text {NTR }}$-KO and WT littermates developed neuropathy in a similar fashion after 24 weeks feeding with the HFD, with a perhaps slight trend for decreased mechanical allodynia found in SC-p75 ${ }^{\mathrm{NTR}}$-KO HFD, as compared with WT HFD (Figure 1c), and significantly reduced sensory and motor NCV observed in a similar fashion across genotypes (Figure 1d and 1e, respectively). No differences were found concerning sensitivity to a noxious thermal heat stimulus between genotypes or upon HFD (data not shown).

This article is protected by copyright. All rights reserved. 


\section{HFD-induced loss of C-fibers upon deletion of Schwann cell p75 ${ }^{\mathrm{NTR}}$ expression}

We next performed sciatic nerve morphological and morphometric analysis by light and electron microscopy to evaluate myelinated axons mediating motor functions and proprioception, and C-fibers mediating nociception. No differences were found in terms of myelinated fiber density (Figure 2a) or g Ratio (Figure 2b) between genotypes or upon HFD. C-fiber densities were also unchanged in the SC-p75 ${ }^{\text {NTR }}$-KO relative to WT on control diet, in accordance with previous results (Gonçalves et al., 2019). However, a significant reduction in C-fiber density was observed upon HFD in nerves from SC-p75 ${ }^{\mathrm{NTR}}-\mathrm{KO}$ as compared to HFD-fed WT controls as well as a trend in comparison with SCp $75^{\mathrm{NTR}}-\mathrm{KO}$ on control diet (Figure 2c and Figure 2d lower panel).

Completely demyelinated axons (Figure 3a), promyelin fibers (Figure 3b) and remyelination (Figure 3c) were observed to the same extent in both genotypes under the HFD. In the present study, nerve infiltration of macrophages in response to the HFD special feeding was not observed (Figure 3d and 3h). In addition, there were no differences in macrophage density between WT and SC-p $75^{\mathrm{NTR}}-\mathrm{KO}$ backgrounds (Figure 3d and $3 \mathrm{~h}$ ). Nevertheless, qualitative and quantitative analysis showed that nerves from SC-p75 ${ }^{\mathrm{NTR}}$-KO HFD mice presented abundant flat sheets of Schwann cell cytoplasmic processes, relative to WT HFD (Figure 3e and 3i), suggestive of axonal degeneration and unmyelinated fiber loss. Further corroborating this notion is the fact that the quantification of axonfree myelin fragments (also called myelin ovoids) (Figure $3 \mathrm{f}$ and $3 \mathrm{j}$ ), despite not statistically significant, suggested a greater extent in severity of axonal atrophy/degeneration in the SC-p75 ${ }^{\mathrm{NTR}}$ KO HFD mice sciatic nerves, as compared with nerves from WT HFD mice. The degree of demyelination/myelin abnormality, observed mainly in small caliber myelinated axons, seemed to be part of the normal nerve turnover (Figure $3 \mathrm{~g}$ and $3 \mathrm{k}$ ).

Altogether, our results suggest an aggravated diabetic neuropathy phenotype when Schwann cells lack $\mathrm{p} 75^{\mathrm{NTR}}$, pointing towards an important role of this receptor in C-fiber survival in the context of type 2 diabetes.

\section{HFD modulation of the inflammatory environment and actin cytoskeleton in WT mice}

To identify differential cellular responses to HFD-induced diabetic neuropathy of SC-p75 ${ }^{\mathrm{NTR}}-\mathrm{KO}$ relative to WT controls, we next performed transcriptional profiling of sciatic nerves by nextgeneration RNA sequencing. Firstly, we assessed gene expression of known markers indicative of sample integrity and appropriate tissue dissections, as previously described (Hinder et al., 2018). As expected, peripheral myelin protein 22 (Pmp22) was identified as highly expressed in the nerve tissue (Figure 4a) while insignificant expression levels of the skeletal muscle-specific transcript myogenic differentiation 1 (Myod1) were found (Figure 4b), demonstrating that there was no muscle contamination in the tissue samples.

Using the NoiSeq method, 207 differentially expressed genes (DEGs) were identified in peripheral nerves of WT mice fed with an HFD compared to control diet, with about $66 \%$ of those genes found to be upregulated (Figure $4 \mathrm{c}$ and $4 \mathrm{~d}$ ). As expected, a significant fraction of genes was found to be involved in lipid metabolism and related to the endocrine and immune systems. Gene Ontology 
Enrichment Analysis with Cytoscape indicated that upregulated genes were mainly associated with the peroxisome proliferator-activated receptor (PPAR) signaling pathway, glycerolipid metabolism, regulation of lipolysis and metabolic pathways (Figure 4e, Table 1), validating presence of type 2 diabetes in our HFD model, with downregulated genes mostly related with actin cytoskeleton (Figure $4 \mathrm{e}$, Table 1). Genes related to immune-mediated processes $(n=49)$ represent a major fraction of the total DEGs, being specially involved in cellular responses to cytokines, regulation of cytokine production, inflammatory response, defense response and leukocyte migration (Table 2).

The 35 most enriched genes in WT HFD relative to WT controls are listed in Table 3. Interestingly, one of the most upregulated genes was macrophage metalloelastase 12 (Mmp-12), a gene also previously linked with type 2 diabetic neuropathy in the $\mathrm{db} / \mathrm{db}$ mouse model (Hinder et al., 2018).

Schwann cell $p 75^{\text {NTR }}$ regulates the neuroinflammatory landscape and promotes phagolysosomal remodeling in HFD-induced neuropathy

Transcriptional analysis of SC-p75 ${ }^{\mathrm{NTR}}$-KO revealed a significant stronger response of HFD in these mice relative to WT, with 412 identified DEGs of which 316 were upregulated and 96 were downregulated (Figure 5a and 5b). As illustrated in the Venn diagram (Figure 5c), 146 DEGs are shared by SC-p75 ${ }^{\mathrm{NTR}}$-KO and WT, being annotated to PPAR signaling pathway, glycerolipid metabolism, fat digestion and absorption, regulation of lipolysis, metabolic pathways, immune responses and regulation of actin cytoskeleton (data not shown), as described for WT in the previous section.

STRING network analysis in Cytoscape, together with a search of gene ontology annotations for the 262 DEGs specifically regulated in SC-p $75^{\mathrm{NTR}}$-KO mice relative to WT mice revealed that $26 \%$ of DEGs were related to the immune system (Table 4, Figure 5d) in processes such as antigen processing and presentation, leukocyte activation and inflammatory response (see Table 4 for details). This observation therefore suggests an increased inflammatory response in the sciatic nerve upon loss of Schwann cell p75 ${ }^{\mathrm{NTR}}$. We also detected significant activation of cellular pathways that were specific for HFD special diet in SC-p75 ${ }^{\mathrm{NTR}}$-KO relative to WT mice, such as the cholesterol metabolism related pathway, cell adhesion, peroxisome, lysosome and phagosome KEGG pathways (Table 5, Figure 5e). Interestingly, 7\% of the SC-p75 ${ }^{\mathrm{NTR}}$-KO specific HFD-induced DEGs in the sciatic nerve belong to the lysosome and phagosome pathways (Table 5), with transcriptional activation of several Cts (Table 6). This result is particularly noteworthy since ultrastructure analysis of sciatic nerves demonstrate that while C-fibers in Remak bundles from WT HFD mice present a normal morphological appearance with the expected distribution of mitochondria and lysosomes (Figure 6a and 6b), nerves from SC-p75 ${ }^{\mathrm{NTR}}$-KO HFD mice exhibited a significant increase in autophagic structures, namely lysosomes and autophagosomes, particularly in C-fibers (Figure 6c-6i), and in flat sheets of Schwann cell cytoplasmic processes (Figure 6j-6n). In these last structures, increase in the autophagy profile (Figure 6l) was attributed to an increase in the number of lysosomes (Figure 6m), as autophagosomes were also found in the very few Schwann cell cytoplasmic processes present in the SC-p75 ${ }^{\text {NTR }}-$ KO control mice (Figure $6 n$ ). 
Based on the combined observations from these sequencing and morphometric analyses, we sought to investigate if accumulation of lysosomes and autophagosomes would translate into accumulation of Cathepsin (Cts) protein in the nervous tissue, indicative of increased lysomal and autophagosomal activity. From our list of upregulated Cts we selected Ctsb, with the highest fold-change observed since it has been reported to be involved in triggering of apoptosis and cell death (Gan et al., 2004; Chwieralski et al., 2006). Longitudinal sections of sciatic nerves from WT and SC-p75 ${ }^{\text {NTR }}$-KO HFD mice were immuno-labeled with a Ctsb antibody and $\beta$ III-tubulin as an axonal marker. Ctsb immunopositive staining was detected in cell-like structures (Figure 7a, upper panel), most likely being Schwann cells, with only a few areas in the SC-p $75^{\mathrm{NTR}}$-KO HFD nerves suggesting presence of Ctsb in the axonal compartment (Figure 7a, upper panel). Since minor Ctsb presence in the axons was detected, we questioned if it could derive from Schwann cell transfer or from sensory neurons through anterograde transport. Furthermore, ultrastructural analysis of sciatic nerves demonstrated increased lysosome and autophagosome structures in C-fibers, further pointing at the importance of analyzing Ctsb levels in the sensory neuronal somas to better envisage Ctsb regulation. Confocal microscopy examination of L4 DRG revealed an increased Ctsb immunolabeling in sensory neurons from SCp75 ${ }^{\text {NTR }}$-KO HFD animals, as compared with the WT HFD counterparts (Figure 7a, lower panel). This result was further validated with quantitative Western blotting, demonstrating a significant increase in Ctsb protein levels in lumbar DRGs from SC-p75 ${ }^{\mathrm{NTR}}-\mathrm{KO}$ HFD relative to WT HFD (Figure 7b). Overall, these results suggest that Ctsb present in the axonal compartment may in principle derive from sensory neurons, and demonstrate an overactivation of phagolysosomal pathways, with increased neuronal Ctsb levels resulting from loss of $\mathrm{p}^{\mathrm{NTR}}$ in Schwann cells, potentially contributing for C-fiber loss in diabetic SC-p75 ${ }^{\mathrm{NTR}}-\mathrm{KO}$ mice.

\section{Discussion}

While decades of research have significantly increased our understanding on diabetic neuropathy, fundamental questions still remain on the cellular and molecular mechanisms underlying this condition. Particularly, the question whether diabetic neuropathy represents a primary axonopathy or rather a Schwannopathy remains controversial. Here, we present data supporting a contribution of Schwannopathy for the progression of axonal degeneration in an HFD model of type 2 diabetes. Using a murine model of prediabetes and obesity, we shown that Remak bundle organization relies on the expression of the multifunctional neurotrophic receptor p75: The specific deletion of $\mathrm{Ngfr}$ expression in Schwann cells intensifies the inflammatory response in type 2 diabetic neuropathy, alongside with 
transcriptional overactivation of genes related to phagolysosomal pathways, ultimately contributing to cell stress and C-fiber degeneration.

The $\mathrm{p} 75^{\mathrm{NTR}}$ receptor belongs to the tumor necrosis factor receptor superfamily, binding all neurotrophins with similar nanomolar affinities (Bothwell, 1995). Despite lacking catalytic intracellular domains, $\mathrm{p} 75^{\mathrm{NTR}}$ is able to signal via several adaptor proteins such as Sortilin, LINGO1 or Nogo-66, or following proteolytic cleavage releasing intracellular domain fragments, resulting in different signaling activation outcomes depending on the cellular context (Nykjaer et al., 2004; Schwab, 2010; Skeldal et al., 2011). In the PNS, p75 ${ }^{\text {NTR }}$ is highly expressed in populations of sensory neurons and glial cells, particularly in pre-myelinating and non-myelinating (Remak) Schwann cells (Cragnolini and Friedman, 2008). However, the specific role of $\mathrm{p} 75^{\mathrm{NTR}}$ in modulating myelination is still not completely understood. Studies with full $\mathrm{Ngfr}^{-/-}$mice demonstrated developmentally thinner myelin sheaths in these animals than those of the WT counterparts (Cosgaya et al., 2002), on the other hand, we have previously characterized how the SC-p75 ${ }^{\mathrm{NTR}}-\mathrm{KO}$ appear to have unperturbed myelination and undergo axonal remyelination identical to WT mice following sciatic crush injury (Gonçalves et al., 2019). Here, we investigated the involvement of Schwann cell p75 ${ }^{\mathrm{NTR}}$ in the pathophysiology of diabetic neuropathy in vivo. For this purpose, we utilized a specific Schwann cell p $75^{\mathrm{NTR}} \mathrm{KO}$ mouse model, where Cre expressed under the MPZ promotor triggers the inversion of a loxP flanked DNA sequence in exon 1 of the $\mathrm{Ngfr}$, replacing $\mathrm{p} 75^{\mathrm{NTR}}$ expression with that of mCherry in the Schwann cells (Boskovic et al., 2014; Gonçalves et al., 2019). Next, we rendered these mice diabetic by the HFD model of obesity and prediabetes, a model extensively characterized in terms of PNS neuropathy progression and proven to be a useful tool for studying diabetes-linked pathology and therapeutic interventions (Groover et al., 2013; O'Brien et al., 2014; 2018). Consistently with previous studies (Rumora et al., 2019; Saika et al., 2019), 24 weeks after special feeding results in obesity, decreased nerve conduction velocities and a neuropathic pain paradigm, validating presence of peripheral neuropathy in both mice strains. We (and others) did not observe any myelin ultrastructural abnormalities or peripheral axonal loss in WT mice fed with the HFD, challenging our understanding of why animals in this diabetic model develop sensory phenotypic abnormalities. Several mechanisms at the cellular level could explain the observed decreased nerve conduction velocities such as short internodal distances (Wu et al., 2012; Arancibia-Cárcamo et al., 2017), incorrect distribution of sodium channels in the nodes (Cummins et al., 2007; Freeman et al., 2016), mitochondrial deficient fibers (Miotto et al., 2018), decrease in type I muscle fibers (Bala et al., 2018), defects in the $\mathrm{Na} / \mathrm{K}$ ATPase (Yorek et al., 1993) or impaired endoneurial nutritive nerve blood flow (Cameron and Cotter, 1995; Richner et al., 2018) all of which are hypotheses that are coming increasingly into focus to explain the pathogenesis of diabetic neuropathy but which still need further investigations. Nevertheless, the lack of nerve ultrastructural deficits represents a limitation of the WT HFD mouse model to represent the observed clinical pathologies (Dyck et al., 1986; Malik, 2014; Osman et al., 2014; Mohseni et al., 2017). Deletion of 75 $^{\mathrm{NTR}}$ in Schwann cells overcame this limitation, with animals presenting a decrease in C-fiber density and more frequent signs of ultrastructural damage such as axonal atrophy and the significant presence of flat sheets of Schwann cell cytoplasmic processes, as an indication of unmyelinated fiber degeneration. Furthermore, the 
significant loss of C-fibers correlate with the observed trend of decreased mechanical allodynia in the SC-p75 ${ }^{\text {NTR }}$-KO HFD, as compared with the WT counterparts. Genetic deletions are often used in the attempt to optimize murine disease models to better resemble the human pathology (Goncalves et al., 2016; Guest and Rahmoune, 2018). The SC-p75 ${ }^{\text {NTR }}$-KO HFD mouse model might therefore be a valuable tool for future diabetic neuropathy research.

In the RNA sequencing analysis, when comparing WT and WT HFD sciatic nerves, the most highly enriched pathways observed were associated with lipid metabolism and the PPAR-regulated transcriptional program, as in accordance with others (Pande et al., 2011; Ahmadian et al., 2013; Li et al., 2016), validating the type 2 diabetic model phenotype. Recent work with the $\mathrm{db} / \mathrm{db}$ mouse model showed that the immune system is involved at all stages of diabetic neuropathy (Hinder et al., 2018), which is also seen in the present study where several immune-related processes were found to be upregulated in the peripheral nerves of WT mice fed with the HFD. Noticeably, the inflammationassociated proteinase Mmp12 was one of the most highly upregulated genes. Like other Mmps, Mmp12 is classically involved in the breakdown of the extracellular matrix (ECM), promoting ECM remodelling during ageing and disease (Goncalves DaSilva and Yong, 2009; Liu et al., 2013). Other pleiotropic roles of Mmp12 include involvement in synaptic remodelling, axonal regeneration (Qin et al., 2016), astrocyte migration, microglia activation (Hansmann et al., 2019) and oligodendrocyte myelin formation (Larsen, 2004; 2006). Additional observations suggest that Mmp12 may also regulate insulin sensitivity and inducible nitric oxide synthase (iNOS) (Lee et al., 2014), potentially exacerbating tissue damage in diabetes. Intriguingly, the plasma levels of Mmp12 were demonstrated to be increased in patients with type 2 diabetes, and further to correlate with atherosclerotic burden and coronary events (Goncalves et al., 2015). Little is known about Mmp12 in the PNS but our data expose the need of further studies addressing whether Mmp12 might be a potential valuable biomarker for diabetic neuropathy, and whether it is playing a protective or destructive role in the course of neuropathy.

Following DEGs related to bioenergetics pathways, our analysis of the SC-p75 ${ }^{\mathrm{NTR}}$-KO HFD mouse model disclosed a significant overactivation of DEGs involved in immune mediated processes relative to that of WT HFD. Specifically, we observed an upregulation of genes involved in complement cascades, antigen processing, natural killer mediated toxicity, B cell and chemokine signaling. It could be speculated that the high endoneurial expression of $\mathrm{p} 75^{\mathrm{NTR}}$ previously identified in diabetic nerves (Conti et al., 2002; Chilton et al., 2004) may be potentiating the nerve repair program and controlling the inflammatory environment. Lack of nerve macrophage infiltration as a consequence of HFD induced obesity together with the similar macrophage density in SC-p75 ${ }^{\mathrm{NTR}}$ KO HFD versus WT HFD further highlights the importance of Schwannopathy for diabetic neuropathy. It is widely known that Schwann cells express a plethora of pattern recognition receptors, such as major histocompatibility complex (MHC) and several toll-like receptors (TLRs), and can secrete cytokines and chemokines upon activation, or function as immune-like cells with phagocytic and antigen presenting capabilities (Ydens et al., 2013). Thus, it is fair to conclude that most of the immune-related pathways found with the RNA sequencing derive from Schwann cell stress rather than from immune cell infiltration. 
Several lines of evidence have supported the importance of neuronal cytoskeleton in the pathogenesis of a number of neurodegenerative disorders (Kevenaar and Hoogenraad, 2015; van den Berg et al., 2017). In the present study, several genes belonging to the actin cytoskeleton compartment were found downregulated in the WT HFD mice sciatic nerves, a response that was more pronounced by the lack of Schwann cell p75 ${ }^{\mathrm{NTR}}$. This down-regulation might explain the delayed and reduced capacity for nerve regeneration after injury of diabetic mice (Ebenezer et al., 2011), potentially indicating impaired axonal transport.

Lysosomal dysfunction has been reported in diabetes, aging and age-related degenerative diseases (Rivera et al., 2010; Tiribuzi et al., 2011; Mattson and Arumugam, 2018; Pasquier et al., 2019). In diabetes, lysosome abnormalities were found in the hippocampus of $\mathrm{db} / \mathrm{db}$ mice and shown to correlated with elevated levels of cholesterol (Sims-Robinson et al., 2015), while in the pancreas, macro-autophagy was demonstrated to be critical for maintenance of $\beta$-cell function in response to cellular stress (Pasquier et al., 2019). In addition to destabilization of lysosomes, diabetes also altered protein levels of Ctsd in the hippocampus of $\mathrm{db} / \mathrm{db}$ mice (Sims-Robinson et al., 2015). In diabetic neuropathy, no major lysosome aberrant function or transcriptional modifications have been documented to date (McGregor et al., 2018). In our study, activation of lysosomal-related pathways was not observed in the WT HFD sciatic nerves; however, Ctsd was found to be overexpressed, suggesting that lysosome stress might become a reality in the periphery over time. Lysosomes are dynamic organelles involved in numerous functions such as cell death, autophagy, endocytic and phagocytic membrane-trafficking pathways (Luzio et al., 2007). Transient lysosomal activation has previously been shown to be essential for $\mathrm{p} 75^{\mathrm{NTR}}$ expression in myelinated Schwann cells during Wallerian degeneration (Jung et al., 2011). Thus, it is possible that Schwann cells lacking p $75^{\mathrm{NTR}}$ become dysfunctional upon exposure to diabetic stressors, intensifying activation of phagolysosomal pathways in associated vulnerable axons. This hypothesis may explain why we here observe significant accumulation of lysosomes in C-fibers as well as the frequent presence of autophagosomes in nerves from SC-p75 ${ }^{\mathrm{NTR}}$-KO diabetic mice. Likewise, expression levels of lysosome-related genes such as several Cts were found to be significantly enriched in the sciatic nerves of these Schwannspecific $\mathrm{p} 75^{\mathrm{NTR}}$ mutant mice on HFD. Cts activation (especially of subtypes B, D, L and S) has long been associated to the onset and progression of kidney disease (Cocchiaro et al., 2017), another major complication of diabetes. According to our results, activation of these enzymes by diabetes in the PNS, and particularly of the lysosomal Ctsb, seems to be dependent on expression of Schwann cell p $75^{\text {NTR }}$. Ctsb is linked to general protein turnover but it may also potentiate inflammation and neuronal death (Gan et al., 2004; Ni et al., 2015). Increased expression of Ctsb at both gene and translational levels have been observed in several cancer types and neurodegenerative diseases (Aggarwal and Sloane, 2014; Lowry and Klegeris, 2018). In this work, we describe an HFD-induced increase in mRNA and protein levels of Ctsb in axons and neurons from mice lacking p $75^{\mathrm{NTR}}$ expression in Schwann cells, thus strengthening the hypothesis of Schwannopathy predisposing neuronal damage observed in diabetic neuropathy.

A strength of the HFD model in contrast to the $\mathrm{db} / \mathrm{db}$ or the ob/ob mouse models of type 2 diabetes, is the advantage of not involving any genetic disruption of the leptin signaling pathway. This may 
prove to be important since our RNA sequencing data demonstrated a 27-fold increased expression levels of the leptin gene (Lep) in the sciatic nerve, indicating that Lep gene regulation is highly involved in type 2 diabetic neuropathy with potential local nerve functions.

Diabetes and complications hereof account for $12 \%$ of global health expenditures, with e.g. healthcare expenses related to diabetic foot care surpassing the combined costs related with cancer treatments (Kerr et al., 2019). This strongly highlights the urge for the development of preventive therapeutic strategies and for a better understanding of the molecular mechanisms underlying development of diabetic neuropathy. In this study, we demonstrate that the deletion of $\mathrm{p}^{\mathrm{NTR}}$ in Schwann cells has a protective role regarding progression of diabetic neuropathy. We identified novel roles for Schwann cell p75 ${ }^{\mathrm{NTR}}$ in the regulation of neuroinflammation and lysosome pathways, which facilitated C-fiber loss consequent to diabetic stress. In this regard, our study supports a hypothesis of increased Schwann cell stress (loss of $\mathrm{p}^{\mathrm{NTR}}$ ) affecting axonal homeostasis and predisposing to neuronal damage under diabetic conditions.

Conflict of interest The authors declare that they have no conflicts of interest.

Data Availability Statement The data that support the findings of this study are available from the corresponding author upon reasonable request.

This article is protected by copyright. All rights reserved. 


\section{References}

Aggarwal, N., \& Sloane, B.F. (2014). Cathepsin B: Multiple roles in cancer. Proteomics - Clinical Applications, 8, 427-437.

Ahmadian, M., Suh, J.M., Hah, N., Liddle, C., Atkins, A.R., Downes, M., Evans, R.M. (2013). PPAR $\gamma$ signaling and metabolism: the good, the bad and the future. Nature Medicine, 19, 557566.

Arancibia-Cárcamo, I.L., Ford, M.C., Cossell, L., Ishida, K., Tohyama, K., Attwell, D. (2017). Node of Ranvier length as a potential regulator of myelinated axon conduction speed. Elife, 6, 521.

Bala, U., Leong, M.P-Y., Lim, C.L., Shahar, H.K., Othman, F., Lai, M-I., Law, Z-K., Ramli, K., Htwe, O., Ling, K-H., Cheah, P-S. (2018). Defects in nerve conduction velocity and different muscle fibre-type specificity contribute to muscle weakness in Ts1Cje Down syndrome mouse model. PLOS ONE, 13, e0197711.

Biessels, G.J., Bril, V., Calcutt, N.A., Cameron, N.E., Cotter, M.A., Dobrowsky, R., Feldman, E.L., Fernyhough, P., Jakobsen, J., Malik, R.A., Mizisin, A.P., Oates, P.J., Obrosova, I.G., PopBusui, R., Russell, J.W., Sima, A.A., Stevens, M.J., Schmidt, R.E., Tesfaye, S., Veves, A., Vinik, A.I., Wright, D.E., Yagihashi, S., Yorek, M.A., Ziegler, D., Zochodne, D.W. (2014). Phenotyping animal models of diabetic neuropathy: a consensus statement of the diabetic neuropathy study group of the EASD (Neurodiab). Journal of the Peripheral Nervous System, 19, 77-87.

Boskovic, Z., Alfonsi, F., Rumballe, B.A., Fonseka, S., Windels, F., Coulson, E.J. (2014). The role of p75NTR in cholinergic basal forebrain structure and function. Journal of Neuroscience, 34, 13033-13038.

Bothwell, M. (1995). Functional interactions of neurotrophins and neurotrophin Receptors. Annual Review of Neuroscience, 18, 223-253.

Boyko, E.J., Seelig, A.D., Ahroni, J.H. (2018). Limb- and person-level risk factors for lower-limb amputation in the prospective Seattle diabetic foot study. Diabetes Care, 41, 891-898.

Cameron, N.E., \& Cotter, M.A. 1995. Neurovascular dysfunction in diabetic rats. Potential contribution of autoxidation and free radicals examined using transition metal chelating agents. Journal of Clinical Investigation, 96, 1159-1163. 
Chao, M.V. (2003). Neurotrophins and their receptors: a convergence point for many signalling pathways. Nature Reviews Neuroscience, 4, 299-309.

Chilton, L., Middlemas, A., Gardiner, N., Tomlinson, D.R. (2004). The p75 neurotrophin receptor appears in plasma in diabetic rats-characterisation of a potential early test for neuropathy. Diabetologia, 47, 1924-1930.

Chwieralski, C.E., Welte, T., Bühling, F. (2006). Cathepsin-regulated apoptosis. Apoptosis, 11, 143-149.

Cocchiaro, P., De Pasquale, V., Morte Della, R., Tafuri, S., Avallone, L., Pizard, A., Moles, A., Pavone, L.M. (2017). The multifaceted role of the lysosomal protease cathepsins in kidney disease. Frontiers in Cell and Developmental Biology, 5, 221.

Conti, G., Scarpini, E., Baron, P., Livraghi, S., Tiriticco, M., Bianchi, R., Vedeler, C., Scarlato, G. (2002). Macrophage infiltration and death in the nerve during the early phases of experimental diabetic neuropathy: a process concomitant with endoneurial induction of IL-1beta and p75NTR. Journal of the Neurological Sciences, 195, 35-40.

Cosgaya, J.M., Chan, J.R., Shooter, E.M. (2002). The neurotrophin receptor p75NTR as a positive modulator of myelination. Science, 298, 1245-1248.

Court, F.A., \& Alvarez, J. (2016). Schwann cell and axon: an interlaced unit-from action potential to phenotype expression. Advances in Experimental Medicine and Biology, 949, 183-201.

Court, F.A., Hendriks, W.T.J., MacGillavry, H.D., Alvarez, J., van Minnen, J. (2008). Schwann cell to axon transfer of ribosomes: toward a novel understanding of the role of glia in the nervous system. Journal of Neuroscience, 28, 11024-11029.

Cragnolini, A.B., \& Friedman, W.J. (2008). The function of p75NTR in glia. Trends in Neurosciences, 31, 99-104.

Cummins, T.R., Sheets, P.L., Waxman, S.G. (2007). The roles of sodium channels in nociception: Implications for mechanisms of pain. Pain, 131, 243-257.

Dey, I., Midha, N., Singh, G., Forsyth, A., Walsh, S.K., Singh, B., Kumar, R., Toth, C., Midha, R. (2013). Diabetic Schwann cells suffer from nerve growth factor and neurotrophin-3 underproduction and poor associability with axons. Glia, 61, 1990-1999.

Dixon, W.J. (1980). Efficient analysis of experimental observations. Annual Review of Pharmacology and Toxicology, 20, 441-462.

Dunnigan, S.K., Ebadi, H., Breiner, A., Katzberg, H.D., Lovblom, L.E., Perkins, B.A., Bril, V. (2013). Conduction slowing in diabetic sensorimotor polyneuropathy. Diabetes Care, 36, 3684-3690.

Dyck, P.J., Lais, A., Karnes, J.L., O'Brien, P., Rizza, R. (1986). Fiber loss is primary and multifocal in sural nerves in diabetic polyneuropathy. Annals of Neurology, 19, 425-439. 
Ebenezer, G.J., O'Donnell, R., Hauer, P., Cimino, N.P., McArthur, J.C., Polydefkis, M. (2011). Impaired neurovascular repair in subjects with diabetes following experimental intracutaneous axotomy. Brain, 134, 1853-1863.

Edition, I.D.A.T. (2015). International Diabetes Federation. IDF Diabetes Atlas, 9th ed. Retrieved from http://www.diabetesatlas.org.

Feldman, E.L., Callaghan, B.C., Pop-Busui, R., Zochodne, D.W., Wright, D.E., Bennett, D.L., Bril, V., Russell, J.W., Viswanathan, V. (2019). Diabetic neuropathy. Nature Reviews Disease Primers, 5, 41-18.

Feldman, E.L., Nave, K-A., Jensen, T.S., Bennett, D.L.H. (2017). New horizons in diabetic neuropathy: mechanisms, bioenergetics, and pain. Neuron, 93, 1296-1313.

Feltri, M.L., D'Antonio, M., Previtali, S., Fasolini, M., Messing, A., Wrabetz, L. (1999). P0-Cre transgenic mice for inactivation of adhesion molecules in Schwann cells. Annals of the New York Academy of Sciences, 883, 116-123.

Freeman, S.A., Desmazières, A., Fricker, D., Lubetzki, C., Sol-Foulon, N. (2016). Mechanisms of sodium channel clustering and its influence on axonal impulse conduction. Cellular and Molecular Life Sciences, 73, 723-735.

Gan, L., Ye, S., Chu, A., Anton, K., Yi, S., Vincent, V.A., Schack von, D., Chin, D., Murray, J., Lohr, S., Patthy, L., Gonzalez-Zulueta, M., Nikolich, K., Urfer, R. (2004). Identification of cathepsin $\mathrm{B}$ as a mediator of neuronal death induced by A $\beta$-activated microglial cells using a functional genomics approach. Journal of Biological Chemistry, 279, 5565-5572.

Gaudet, A.D., Popovich, P.G., Ramer, M.S. (2011). Wallerian degeneration: gaining perspective on inflammatory events after peripheral nerve injury. Journal of Neuroinflammation, 8, 110-13.

Gonçalves DaSilva, A., \& Yong, V.W. (2009). Matrix metalloproteinase-12 deficiency worsens relapsing-remitting experimental autoimmune encephalomyelitis in association with cytokine and chemokine dysregulation. American Journal of Pathology, 174, 898-909.

Gonçalves, I., Bengtsson, E., Colhoun, H.M., Shore, A.C., Palombo, C., Natali, A., Edsfeldt, A., Dunér, P., Fredrikson, G.N., Björkbacka, H., Östling, G., Aizawa, K., Casanova, F., Persson, M., Gooding, K., Strain, D., Khan, F., Looker, H.C., Adams, F., Belch, J., Pinnoli, S., Venturi, E., Kozakova, M., Gan, L-M., Schnecke, V., Nilsson, J. (2015). Elevated plasma levels of MMP-12 are associated with atherosclerotic burden and symptomatic cardiovascular disease in subjects with type 2 diabetes. Arteriosclerosis, Thrombosis, and Vascular Biology, 35, 17231731.

Gonçalves, N.P., Gonçalves, P., Magalhães, J., Ventosa, M., Coelho, A.V., Saraiva, M.J. (2016). Tissue remodeling after interference RNA mediated knockdown of transthyretin in a familial amyloidotic polyneuropathy mouse model. Neurobiology of Aging, 47, 91-101. 
Gonçalves, N.P., Mohseni, S., Soury, El M., Ulrichsen, M., Richner, M., Xiao, J., Wood, R.J., Andersen, O.M., Coulson, E.J., Raimondo, S., Murray, S.S., Vægter, C.B. (2019). Peripheral nerve regeneration is independent from Schwann cell p75NTR expression. Frontiers in Cellular Neuroscience, 13, 235.

Gonçalves, N.P., Vægter, C.B., Andersen, H., Østergaard, L., Calcutt, N.A., Jensen, T.S. (2017). Schwann cell interactions with axons and microvessels in diabetic neuropathy. Nature Reviews Neurology, 13, 135-147.

Grisold, A., Callaghan, B.C., Feldman, E.L. (2017). Mediators of diabetic neuropathy: is hyperglycemia the only culprit? Current Opinion in Endocrinology, Diabetes and Obesity, 24, 103-111.

Groover, A.L., Ryals, J.M., Guilford, B.L., Wilson, N.M., Christianson, J.A., Wright, D.E. (2013). Exercise-mediated improvements in painful neuropathy associated with prediabetes in mice. Pain, 154, 2658-2667.

Guest, P.C., \& Rahmoune, H. (2018). Characterization of the db/db Mouse Model of Type 2 Diabetes. Methods in Molecular Biology, 1916, 195-201.

Halim, N.D., Mcfate, T., Mohyeldin, A., Okagaki, P., Korotchkina, L.G., Patel, M.S., Jeoung, N.H., Harris, R.A., Schell, M.J., Verma, A. (2010). Phosphorylation status of pyruvate dehydrogenase distinguishes metabolic phenotypes of cultured rat brain astrocytes and neurons. Glia, 58, 1168-1176.

Hansmann, F., Zhang, N., Herder, V., Leitzen, E., Baumgärtner, W. (2019). Delayed Astrogliosis Associated with Reduced M1 Microglia Activation in Matrix Metalloproteinase 12 Knockout Mice during Theiler's Murine Encephalomyelitis. International Journal of Molecular Sciences 20, 1702.

Hargreaves, K., Dubner, R., Brown, F., Flores, C., Joris, J. (1988). A new and sensitive method for measuring thermal nociception in cutaneous hyperalgesia. Pain, 32, 77-88.

Hinder, L.M., Murdock, B.J., Park, M., Bender, D.E., O'Brien, P.D., Rumora, A.E., Hur, J., Feldman, E.L. (2018). Transcriptional networks of progressive diabetic peripheral neuropathy in the $\mathrm{db} / \mathrm{db}$ mouse model of type 2 diabetes: An inflammatory story. Experimental Neurology, 305, 33-43.

Hinder, L.M., O'Brien, P.D., Hayes, J.M., Backus, C., Solway, A.P., Sims-Robinson, C., Feldman, E.L. (2017). Dietary reversal of neuropathy in a murine model of prediabetes and metabolic syndrome. Disease Models \& Mechanisms, 10, 717-725.

Jessen, K.R., Arthur-Farraj, P. (2019). Repair Schwann cell update: Adaptive reprogramming, EMT, and stemness in regenerating nerves. Glia, 67, 421-437.

Jessen, K.R., \& Mirsky, R. (2005). The origin and development of glial cells in peripheral nerves. Nature Reviews Neuroscience, 6, 671-682. 
Jia, L., Chopp, M., Wang, L., Lu, X., Szalad, A., Zhang, Z.G. (2018). Exosomes derived from highglucose-stimulated Schwann cells promote development of diabetic peripheral neuropathy. FASEB Journal, 32, fj201800597R.

Jung, H., Yoon, B.C., Holt, C.E. (2012). Axonal mRNA localization and local protein synthesis in nervous system assembly, maintenance and repair. Nature Reviews Neuroscience, 13, 308-324.

Jung, J., Cai, W., Jang, S.Y., Shin, Y.K., Suh, D.J., Kim, J.K., Park, H.T. (2011). Transient lysosomal activation is essential for p75 nerve growth factor receptor expression in myelinated Schwann cells during Wallerian degeneration. Anatomy \& Cell Biology, 44, 41.

Kerr, M., Barron, E., Chadwick, P., Evans, T., Kong, W.M., Rayman, G., Sutton-Smith, M., Todd, G., Young, B., Jeffcoate, W.J. (2019). The cost of diabetic foot ulcers and amputations to the National Health Service in England. Diabetic Medicine, 36, 995-1002.

Kevenaar, J.T., \& Hoogenraad, C.C. (2015). The axonal cytoskeleton: from organization to function. Frontiers in Molecular Neuroscience, 8, 479.

Kim, D., Langmead, B., Salzberg, S.L. (2015). HISAT: a fast spliced aligner with low memory requirements. Nature Methods, 12, 357-360.

Langmead, B., Trapnell, C., Pop, M., Salzberg, S.L. (2009). Ultrafast and memory-efficient alignment of short DNA sequences to the human genome. Genome Biology, 10, R25.

Larsen, P.H., \& Yong, V.W. (2004). The expression of matrix metalloproteinase-12 by oligodendrocytes regulates their maturation and morphological differentiation. Journal of Neuroscience, 24, 7597-7603.

Larsen PH., Da Silva, A.G., Conant, K., Yong, V.W. (2006). Myelin formation during development of the CNS is delayed in matrix metalloproteinase- 9 and -12 null mice. Journal of Neuroscience, 26, 2207-2214.

Lee, J-T., Pamir, N., Liu, N-C., Kirk, E.A., Averill, M.M., Becker, L., Larson, I., Hagman, D.K., Foster-Schubert, K.E., van Yserloo, B., Bornfeldt, K.E., LeBoeuf, R.C., Kratz, M., Heinecke, J.W. (2014). Macrophage metalloelastase (MMP12) regulates adipose tissue expansion, insulin sensitivity, and expression of inducible nitric oxide synthase. Endocrinology, 155, 3409-3420.

Li, Y., Ma, W., Xie, C., Zhang, M., Yin, X., Wang, F., Xu, J., Shi, B. (2016). Identification of genes and signaling pathways associated with diabetic neuropathy using a weighted correlation network analysis. Medicine, 95, e5443.

Liu, Y., Zhang, M., Hao, W., Mihaljevic, I., Liu, X., Xie, K., Walter, S., Fassbender, K. (2013). Matrix metalloproteinase-12 contributes to neuroinflammation in the aged brain. Neurobiology of Aging, 34, 1231-1239.

Lopez-Verrilli, M.A., Picou, F., Court, F.A. (2013). Schwann cell-derived exosomes enhance axonal regeneration in the peripheral nervous system. Glia, 61, 1795-1806. 
Lowry, J.R., \& Klegeris, A. (2018). Emerging roles of microglial cathepsins in neurodegenerative disease. Brain Research Bulletin, 139, 144-156.

Luzio, J.P., Pryor, P.R., Bright, N.A. (2007). Lysosomes: fusion and function. Nature Reviews Molecular Cell Biology, 8, 622-632.

Malik, R.A. (2014). Pathology of human diabetic neuropathy. Handbook of Clinical Neurology. 126, 249-259.

Mattson, M.P., \& Arumugam, T.V. (2018). Hallmarks of brain aging: adaptive and pathological modification by metabolic states. Cell Metabolism, 27, 1176-1199.

McGregor, B.A., Eid, S., Rumora, A.E., Murdock, B., Guo, K., de Anda-Jáuregui, G., Porter, J.E., Feldman, E.L., Hur, J. (2018). Conserved transcriptional signatures in human and murine diabetic peripheral neuropathy. Scientific Reports, 8, 17678.

Miotto, P.M., LeBlanc, P.J., Holloway, G.P. (2018). High-fat diet causes mitochondrial dysfunction as a result of impaired ADP sensitivity. Diabetes, 67, 2199-2205.

Mizisin, A.P. (2014). Mechanisms of diabetic neuropathy: Schwann cells. Handbook of Clinical Neurology, 126, 401-428.

Mohseni, S., Badii, M., Kylhammar, A., Thomsen, N.O.B., Eriksson, K-F., Malik, R.A., Rosén, I., Dahlin, L.B. (2017). Longitudinal study of neuropathy, microangiopathy, and autophagy in sural nerve: Implications for diabetic neuropathy. Brain and Behavior, 7, e00763.

Ni, J., Wu, Z., Peterts, C., Yamamoto, K., Qing, H., Nakanishi, H. (2015). The critical role of proteolytic relay through cathepsins $\mathrm{B}$ and $\mathrm{E}$ in the phenotypic change of microglia/macrophage. Journal of Neuroscience, 35, 12488-12501.

Nykjaer, A., Lee, R., Teng, K.K., Jansen, P., Madsen, P., Nielsen, M.S., Jacobsen, C., Kliemannel, M., Schwarz, E., Willnow, T.E., Hempstead, B.L., Petersen, C.M. (2004). Sortilin is essential for proNGF-induced neuronal cell death. Nature, 427, 843-848.

O'Brien, P.D., Hinder, L.M., Rumora, A.E., Hayes, J.M., Dauch, J.R., Backus, C., Mendelson, F.E., Feldman, E.L. (2018). Juvenile murine models of prediabetes and type 2 diabetes develop neuropathy. Disease Models \& Mechanisms, 11, dmm037374.

O'Brien, P.D., Sakowski, S.A., Feldman, E.L. (2014). Mouse models of diabetic neuropathy. Journal of the Institute for Laboratory Animal Research, 54, 259-272.

Osman, A.A.M., Dahlin, L.B., Thomsen, N.O.B., Mohseni, S. (2014). Autophagy in the posterior interosseous nerve of patients with type 1 and type 2 diabetes mellitus: an ultrastructural study. Diabetologia, 58, 625-632.

Pan, S., \& Chan, J.R. (2017). Regulation and dysregulation of axon infrastructure by myelinating glia. Journal of Cell Biology, 216, 3903-3916. 
Pande, M., Hur, J., Hong, Y., Backus, C., Hayes, J.M., Oh, S.S., Kretzler, M., Feldman, E.L. (2011). Transcriptional profiling of diabetic neuropathy in the BKS db/db mouse: A model of type 2 diabetes. Diabetes, 60, 1981-1989.

Pasquier, A., Vivot, K., Erbs, E., Spiegelhalter, C., Zhang, Z., Aubert, V., Liu, Z., Senkara, M., Maillard, E., Pinget, M., Kerr-Conte, J., Pattou, F., Marciniak, G., Ganzhorn, A., Ronchi, P., Schieber, N.L., Schwab, Y., Saftig, P., Goginashvili, A., Ricci, R. (2019). Lysosomal degradation of newly formed insulin granules contributes to $\beta$ cell failure in diabetes. Nature Communications, 10, 9-14.

Qin, J., Zha, G-B., Yu, J., Zhang, H-H., Yi, S. (2016). Differential temporal expression of matrix metalloproteinases following sciatic nerve crush. Neural Regeneration Research, 11, 1165.

Richner, M., Ferreira, N., Dudele, A., Jensen, T.S., Vægter, C.B., Gonçalves, N.P. (2018). Functional and structural changes of the blood-nerve-barrier in diabetic neuropathy. Frontiers Neuroscience, 12, 1038.

Rivera, J.F., Gurlo, T., Daval, M., Huang, C.J., Matveyenko, A.V., Butler, P.C., Costes, S. (2010). Human-IAPP disrupts the autophagy/lysosomal pathway in pancreatic $\beta$-cells: protective role of p62-positive cytoplasmic inclusions. Cell Death and Differentiation, 18, 415-426.

Rumora, A.E., LoGrasso, G., Hayes, J.M., Mendelson, F.E., Tabbey, M.A., Haidar, J.A., Lentz, S.I., Feldman, E.L. (2019). The divergent roles of dietary saturated and monounsaturated fatty acids on nerve function in murine models of obesity. Journal of Neuroscience, 39, 3770-3781.

Saika, F., Kiguchi, N., Matsuzaki, S., Kobayashi, D., Kishioka, S. (2019). Inflammatory macrophages in the sciatic nerves facilitate neuropathic pain associated with type 2 diabetes mellitus. Journal of Pharmacology and Experimental Therapeutics, 368, 535-544.

Scarpini, E., Conti, G., Chianese, L., Baron, P., Pizzul, S., Basellini, A., Livraghi, S., Scarlato, G. (1996). Induction of p75NGFR in human diabetic neuropathy. Journal of The Neurological Sciences, 135, 55-62.

Schwab, M.E. (2010). Functions of Nogo proteins and their receptors in the nervous system. Nature Reviews Neuroscience, 11, 799-811.

Shannon, P., Markiel, A., Ozier, O., Baliga, N.S., Wang, J.T., Ramage, D., Amin, N., Schwikowski, B., Ideker, T. (2003). Cytoscape: a software environment for integrated models of biomolecular interaction networks. Genome Research, 13, 2498-2504.

Sims-Robinson, C., Bakeman, A., Rosko, A., Glasser, R., Feldman, E.L. (2015). The Role of Oxidized Cholesterol in Diabetes-Induced Lysosomal Dysfunction in the Brain. Molecular Neurobiology, 53, 2287-2296.

Skeldal, S., Matusica, D., Nykjaer, A., Coulson, E.J. (2011). Proteolytic processing of the p75 neurotrophin receptor: A prerequisite for signalling?: Neuronal life, growth and death signalling 
are crucially regulated by intra-membrane proteolysis and trafficking of p75(NTR). Bioessays, 33, 614-625.

Szklarczyk, D., Morris, J.H., Cook, H., Kuhn, M., Wyder, S., Simonovic, M., Santos, A., Doncheva, N.T., Roth, A., Bork, P., Jensen, L.J., Mering von, C. (2017). The STRING database in 2017: quality-controlled protein-protein association networks, made broadly accessible. Nucleic Acids Research, 45, D362-D368.

Tarazona, S., Garcia-Alcalde, F., Dopazo, J., Ferrer, A., Conesa, A. (2011). Differential expression in RNA-seq: A matter of depth. Genome Research, 21, 2213-2223.

Tiribuzi, R., Orlacchio, A., Crispoltoni, L., Maiotti, M., Zampolini, M., De Angeliz, M., Mecocci, P., Cecchetti, R., Bernardi, G., Datti, A., Martino, S., Orlacchio, A. (2011). Lysosomal $\beta$ galactosidase and $\beta$-hexosaminidase activities correlate with clinical stages of dementia associated with Alzheimer's disease and type 2 diabetes mellitus. Journal of Alzheimer's Disease, 24, 785-797.

van den Berg, R., Hoogenraad, C.C., Hintzen, R.Q. (2017). Axonal transport deficits in multiple sclerosis: spiraling into the abyss. Acta Neuropathologica, 134, 1-14.

Wu, L-M.N., Williams, A., Delaney, A., Sherman, D.L., Brophy, P.J. (2012). Increasing internodal distance in myelinated nerves accelerates nerve conduction to a flat maximum. Current Biology, 22, 1957-1961.

Ydens, E., Lornet, G., Smits, V., Goethals, S., Timmerman, V., Janssens, S. (2013). The neuroinflammatory role of Schwann cells in disease. Neurobiology of Disease, 55, 95-103.

Yorek, M.A., Wiese, T.J., Davidson, E.P., Dunlap, J.A., Stefani, M.R., Conner, C.E., Lattimer, S.A., Kamijo, M., Greene, D.A., Sima, A.A.F. (1993). Reduced motor nerve conduction velocity and $\mathrm{Na}+-\mathrm{K}+-\mathrm{ATPase}$ activity in rats maintained on L-fucose diet: Reversal by myoinositol supplementation. Diabetes, 42, 1401-1406.

\section{Figure legends:}

This article is protected by copyright. All rights reserved. 
FIGURE 1 The $60 \%$ high fat-rich diet causes neuropathy in prediabetic mice. (a) The Ngfr mutant gene $\left(\mathrm{p} 75^{\mathrm{fl} / \mathrm{fl}}\right.$ ) and the inversion approach used to produce SC-p75 ${ }^{\mathrm{NTR}}-\mathrm{KO}$ mice. In cells expressing cre recombinase, the loxP-flanked region inverts to generate transgenic animals that express mCherry rather than $\mathrm{p} 75^{\mathrm{NTR}}$ from the endogenous $\mathrm{Ngfr}$ promoter in Schwann cells. UTR codes for untranslated region. Transgenic and WT littermates were then put on a control diet (CD) or HFD from the 5 weeks of age, for 24 weeks. (b) Metabolic phenotyping of mice with body weight measurements over time, during the 24 weeks of special feeding. Results from neuropathy phenotyping were obtained by using the Von Frey test (c), sensory (d) and motor nerve conduction velocities (e) (SNCV and MNCV, respectively). All data represent mean \pm SEM from 10-11 animals per group. Two-way ANOVA with Tukey's multiple-comparisons test ${ }^{*} \mathrm{p}<0.05$, ${ }^{* *} \mathrm{p}<0.01$, ${ }^{* * *} \mathrm{p}<0.001$.

FIGURE 2 Deletion of p75 ${ }^{\mathrm{NTR}}$ in Schwann cells leads to a significant decrease in C-fiber density, but is not associated with loss of myelinated fibers, upon HFD special feeding. Histograms obtained from the morphometrical quantification of (a) myelinated fibers, (b) g Ratio and (c) unmyelinated fibers. (d) Representative TEM images of unmyelinated axons (C-fibers, yellow mask) in the sciatic nerves of WT and SC-p75 ${ }^{\mathrm{NTR}}$-KO mice fed with a control or HFD. In lower right picture in (d), notice the presence of unmyelinated axons (yellow mask) together with many flattened Schwann cell processes that usually are formed after loss of unmyelinated axons. An abnormal myelin-Schwann cell configuration is marked (white asterisk). Two-way ANOVA with Tukey's multiple-comparisons test ${ }^{*} \mathrm{p}<0.05 ; \mathrm{n}=4-5$ mice per genotype; scale bar $2 \mu \mathrm{m}$.

FIGURE 3 Morphological ultrastructural abnormalities are more prominent in sciatic nerves from mice fed with an HFD, in the absence of p75 ${ }^{\text {NTR }}$ in Schwann cells (SC-p75 ${ }^{\text {NTR }}$-KO HFD mice). (a) Picture showing a completely demyelinating axon (> $1.5 \mu \mathrm{m}$ diameter; blue star) (b) Image showing several isolated unmyelinated axons and a Remak bundle (yellow mask) with an axon being myelinated depicted with a black asterisk (scale bar $2 \mu \mathrm{m}$ ). (c) Shows a remyelinated axon (black asterisk; scale bar $2 \mu \mathrm{m}$ ). A plasma cell-like structure with rough endoplasmic reticulum can also be seen. (d) A macrophage engulfing myelin fragments is highlighted with a white arrow. (e) Denotes an unmyelinated axon with a diameter above $1.5 \mu \mathrm{m}$ (blue star) and flat sheets of Schwann cell processes (pink stars) enclosed by a common basement membrane (black arrows), formed usually after degeneration of unmyelinated axons. These structures are highly present in the nerves from SCp75 ${ }^{\text {NTR }}$-KO HFD mice, as illustrated in the graph chart in (i). A yellow star highlights a small unmyelinated axon. (f) Exhibit a Schwann cell profile containing axon-free myelin, with the thin cytoplasmic collar and the basal lamina highlighted with a red mask (in areas where it can be identified), and (g) shows a transverse section of a small caliber axon with thin and disorganized myelin. Quantification of (h) macrophage, (i) flat sheets of Schwann cell processes, (j) axon-free myelin and $(\mathrm{k})$ demyelinating fiber densities, normalized against the nerve area, are illustrated in the bar charts. Two-way ANOVA with Tukey's multiple-comparisons test ${ }^{*} \mathrm{p}<0.05$. TEM sciatic nerve sections from $n=4-5$ mice per genotype were analyzed.

FIGURE 4 HFD feeding in WT mice triggers activation of diabetes-related pathways in the peripheral nerve, alongside with downregulation of actin cytoskeleton. FPKM values for (a) Pmp22 and (b) Myod1, obtained with RNA sequencing of sciatic nerves from all the mice groups analyzed were plotted, to show nerve specificity and lack of muscle contamination, respectively. (c) log10 gene expression level graph and a (d) numerical graph demonstrating the upregulated (in orange) and downregulated (in blue) genes in WT HFD mice relative to the WT group having the control diet. (e) 
STRING network of regulated genes in sciatic nerves from WT HFD mice. The 207 regulated genes produced a network of 93 genes in the STRING app in Cytoscape. The genes in the ellipse are upregulated and the genes in rectangular are downregulated in WT HFD. Genes involved with metabolic pathways are identified with a yellow boarder, those related with the PPAR signaling pathway have a red fill, glycerolipid metabolism has white writing and regulation of lipolysis is with a blue border. Genes belonging to actin cytoskeleton are recognized with green filling. $\mathrm{n}=5$ mice per group. Data was analyzed accordingly to the NOIseq method.

FIGURE 5 Glial p75 ${ }^{\text {NTR }}$ modulates the inflammatory landscape and activation of lysosome and phagosome pathways in mice fed with an HFD. (a) log10 gene expression level graph and (b) a numerical graph demonstrating the upregulated (in orange) and downregulated (in blue) genes in SCp $75^{\mathrm{NTR}}$-KO mice fed with HFD relative to the SC-p75 ${ }^{\mathrm{NTR}}$-KO group having the control diet. (c) Venn diagram illustrating WT vs WT HFD (blue) and p75 vs p75 HFD (yellow) with 146 DEG's in common. 262 genes are solely differently expressed in mice fed with HFD when Schwann cells lack p $75^{\mathrm{NTR}}$ while 61 genes are solely differently expressed in the WT situation and thus not depending on Schwann cell p75 ${ }^{\mathrm{NTR}}$ expression. (d) STRING network for those 262 regulated genes only activated in sciatic nerves from SC-p75 ${ }^{\text {NTR }}$-KO HFD mice. The 262 regulated genes produced a network of 162 genes in the STRING app in Cytoscape. The genes in the ellipse are upregulated and the genes in rectangular are downregulated in SC-p75 ${ }^{\mathrm{NTR}}-\mathrm{KO}$ HFD. Immune-related genes are depicted with a red boarder while those involved in cell adhesion, cholesterol, lysosome, phagosome and peroxisome pathways present a blue fill. (e) The heatmap shows FPKM values (normalized with min-max normalization) for all 4 analyzed groups. The genes are differently regulated only in the p75 vs p75 HFD condition and are annotated to cell adhesion (CAMs), phagosome, lysosome, cholesterol and peroxisome-related genes. $\mathrm{n}=5$ mice per group. Statistics was based on the NOIseq method with fold changes $\geq 2$.

FIGURE 6 Activation of lysosome and phagosome gene pathways in SC-p $75^{\mathrm{NTR}}-\mathrm{KO}$ mice fed with an HFD correlate with ultrastructural findings in C-fibers and flat sheets of Schwann cell cytoplasmic processes. (a) and (b) show the normal morphological appearance of Remak bundles in WT HFD, with some mitochondria highlighted with black arrows and one lysosome pointed with a blue arrow (scale bar $1 \mu \mathrm{m}$ ). (c)-(f) are representative TEM pictures illustrating accumulation of lysosomes and autophagosomes in C-fibers from SC-p75 ${ }^{\mathrm{NTR}}$-KO with HFD. (c) Normal mitochondria in Remak bundles are pointed with black arrows, while several lysosomes (blue arrows) can be observed in the C-fiber axoplasm (scale bar $1 \mu \mathrm{m}$ ). (d) Orange inset zooms in two C-fibers, one containing two lysosomes (blue arrows) and one containing several autophagosome-like structures (yellow arrow) (scale bar $500 \mathrm{~nm}$ ). (e) A single C-fiber containing several lysosomes (blue arrows), suggestive of cell stress (scale bar $500 \mathrm{~nm}$ ). (f) Shows two autophagosomes in a C-fiber (yellow arrows) with very clear double membrane, characteristic of these cellular components (scale bar $500 \mathrm{~nm}$ ). (g) Graph chart represents quantification of the number of autophagic structures present in c-fibers, from all the mice groups analyzed. Average number of lysosomes (h) and autophagosomes (i) per C-fiber are depicted. (j) Illustrates a multivesicular body (red arrow) and a lysosome (blue arrow) in C-fibers in a bundle of Schwann cell cytoplasmic processes (scale bar $500 \mathrm{~nm}$ ). In (k), Schwann cell cytoplasmic processes are represented with an axon (blue star) containing multiple vacuole-like bodies (red arrow) and a vesicle holding many small mitochondria (pink arrow; scale bar $500 \mathrm{~nm}$ ). (l), (m) and (n) denote quantification of autophagy related structures, namely lysosomes and autophagosomes, per bundle of Schwann cell (SC) cytoplasmic processes with common basement membrane, with individual 
quantification represented in separate charts. Statistical analysis was performed with Two-way ANOVA with Tukey's multiple-comparisons test; ${ }^{*} \mathrm{p}<0.05$, ${ }^{* *} \mathrm{p}<0.01,{ }^{* * *} \mathrm{p}<0.001 ; \mathrm{n}=4-5$ mice per genotype.

FIGURE 7 Mice lacking p75 ${ }^{\mathrm{NTR}}$ in Schwann cells display enhanced Ctsb in the PNS after HFDinduced diabetic neuropathy. (a) Representative confocal microscopy images of a triple staining between Ctsb (green), $\beta$ III-tubulin (red) and Hoechst (blue) in the sciatic nerve (upper panel) and L4 DRG (bottom panel) from SC-p75 ${ }^{\text {NTR }}$-KO mice with HFD and WT HFD littermates (scale bar 50 $\mu \mathrm{m})$. White arrows point to Ctsb immuno-positive labeling in cell-like structures, while the yellow thicker arrows denote Ctsb co-localization with $\beta$ III-tubulin, indicating Ctsb presence in the axonal compartment. (b) Representative immunoblot and densitometry analysis for Ctsb, normalized against $\beta$-actin, from lumbar DRGs (unpaired t test, ${ }^{* *} \mathrm{p}<0.01 ; \mathrm{n}=5$ mice per genotype, data is presented as mean \pm SEM).

This article is protected by copyright. All rights reserved. 


\begin{tabular}{|c|c|c|}
\hline Upregulated & p-value & Enriched Genes \\
\hline $\begin{array}{l}\text { PPAR signaling } \\
\text { pathway }\end{array}$ & $4.32 \mathrm{E}-5$ & Plin2|Lpl|Adipoq|Fabp5|Aqp7|Plin1|Acsl1|Dbi \\
\hline $\begin{array}{l}\text { Glycerolipid } \\
\text { metabolism }\end{array}$ & 0.0045 & Lpl|Lipf|Agpat2|Dgat2|Pnpla3 \\
\hline $\begin{array}{l}\text { Regulation of } \\
\text { lipolysis }\end{array}$ & 0.0045 & Lipe $\mid$ Tshr $\mid$ Aqp7|Plin1|Ptger3 \\
\hline $\begin{array}{l}\text { Metabolic } \\
\text { pathways }\end{array}$ & 0.0341 & $\begin{array}{l}\text { Ckm } \mid \text { Tph2 } \mid \text { Galntl2 } \mid \text { Gpt } \mid \text { Aldh1a7|Lipf } \mid \text { Cyp2e1 } \mid \\
\text { Agpat2|Atp6v0d2|Dgat2|Prps1|Acsl1|Nnmt } \mid \text { Pnpla3|Fasn } \mid \\
\text { Gstz1|Pcx } \mid \text { Acsm3|Agxt2l1|Aoc3 }\end{array}$ \\
\hline Downregulated & p-value & Enriched Genes \\
\hline $\begin{array}{l}\text { Actin } \\
\text { Cytoskeleton }\end{array}$ & 0.006 & $\begin{array}{l}\text { Actn3|Myh4|Myl1|Mylpf|Acta1|Cib2|Myoz1|Tnnc2|Adam8| } \\
\text { Synpo2|Mybpc2 }\end{array}$ \\
\hline
\end{tabular}

Table 1 Upregulated KEGG pathways in the WT HFD versus WT counterparts.

Most of the downregulated genes belong to the actin cytoskeleton component.

This article is protected by copyright. All rights reserved. 


\begin{tabular}{|c|c|c|}
\hline $\begin{array}{l}\text { Immune } \\
\text { mediated process }\end{array}$ & p-value & Enriched Genes \\
\hline $\begin{array}{l}\text { Response to } \\
\text { Cytokine }\end{array}$ & 5.6E-4 & $\begin{array}{l}\text { Il7r } \mid \text { Saa3 } \mid \text { Serpina3n } \mid \text { Fos } \mid \text { Adipoq } \mid \text { Gpd1 } \mid \text { Cxcl13 } \mid \text { Acsl1 } \mid \\
\text { Ubd } \mid \text { Oxtr } \mid \text { Fasn } \mid \text { Zfp36 } \mid \text { Ifi205 } \mid \text { Wdnm1-like } \mid \text { Junb } \mid \\
\text { Lep } \mid \text { Egr1 } \mid \text { Serpina3c } \mid \text { Il1rn }\end{array}$ \\
\hline $\begin{array}{l}\text { Acute phase } \\
\text { response }\end{array}$ & $1.79 \mathrm{E}-5$ & Saa3|Serpina3n|Orm1| Ptger3|Hp|Cd163|Il1rn \\
\hline $\begin{array}{l}\text { Inflammatory } \\
\text { response }\end{array}$ & 0.0056 & $\begin{array}{l}\text { Adipoq|Sucnr1|Ptger3|Zfp36|S100a8|Lep|Aoc3|Adam8|Saa3 } \\
\text { Serpina3n|Cela1|Cxcl13|Orm1|Hp|Cd163|Il1rn }\end{array}$ \\
\hline $\begin{array}{l}\text { Leucocyte } \\
\text { differentiation }\end{array}$ & 0.0026 & $\begin{array}{l}\text { Il7r|Tshr|Fam20c|Cd1d1|Ubd|Fasn|Junb|Lep|Egr1|Lgals1| } \\
\text { Adam8 }\end{array}$ \\
\hline $\begin{array}{l}\text { Regulation of } \\
\text { cytokine } \\
\text { production }\end{array}$ & 0.0306 & $\begin{array}{l}\text { Mmp12|Lpl|Adipoq|Agpat2|Fcna } \mid \text { Cd1d1| } \\
\text { Errfi1|Gpnmb|Zfp36|Lep|Egr1|Adam8 }\end{array}$ \\
\hline Cell chemotaxis & 0.0363 & Saa3|Cxcl14|Cxcl13|S100a8|Adam8|Lgals3 \\
\hline Defense response & 0.0102 & $\begin{array}{l}\text { Saa3 } \mid \text { Serpina3n } \mid \text { Cela1 } \mid \text { Cxcl13 } \mid \text { Fcna } \mid \text { Cd1d1 } \mid \\
\text { Orm1 } \mid \text { Itgax } \mid \text { Ubd } \mid \text { Ptger3 } \mid \text { Cfd } \mid \text { S100a8 } \mid \\
\text { Hp } \mid \text { Aoc3 } \mid \text { Adam8 } \mid \text { Cd163 } \mid \text { Il1rn } \mid \text { Lgals3 } \mid \text { Dbi }\end{array}$ \\
\hline $\begin{array}{l}\text { Regulation of } \mathrm{T} \\
\text { cell apoptotic } \\
\text { process }\end{array}$ & 0.0114 & Il7r|Adam8|Tsc22d3|Lgals3 \\
\hline $\begin{array}{l}\text { Leukocyte } \\
\text { activation }\end{array}$ & 0.0391 & $\begin{array}{l}\text { Il7r } \mid \text { Tshr } \mid \text { Sucnr1 } \mid \text { Cd1d1 } \mid \text { Itgad } \mid \text { Ubd } \mid \text { Lat } 2 \mid \\
\text { Lep } \mid \text { Egr1 } \mid \text { Lgals1 }\end{array}$ \\
\hline $\begin{array}{l}\text { Toll-like receptor } \\
4 \text { binding }\end{array}$ & 0.0392 & Saa3|S100a8 \\
\hline $\begin{array}{l}\text { Leukocyte } \\
\text { migration }\end{array}$ & 0.0423 & S100a8 |Cxcl13|Aoc3|Adam8|Lgals3|Lep \\
\hline $\begin{array}{l}\text { Regulation of } \\
\text { tumor necrosis } \\
\text { factor production }\end{array}$ & 0.0474 & Adipoq|Errfi1|Gpnmb|Zfp36|Lep \\
\hline
\end{tabular}

Table 2 Immune system related processes differentially regulated in the WT HFD, as compared to WT mice feed with the control diet.

This article is protected by copyright. All rights reserved. 


\begin{tabular}{|c|c|c|c|}
\hline $\begin{array}{l}\text { Upregulated } \\
\text { Gene }\end{array}$ & Protein name & $\begin{array}{l}\text { Fold } \\
\text { change }\end{array}$ & Log2Ratio \\
\hline Tph2 & Tryptophan 5-hydroxylase 2 & 530.95 & 9.052 \\
\hline Mmp12 & Matrix metalloproteinase 12 & 101.51 & 6.67 \\
\hline Ubd & Ubiquitin D & 86.74 & 6.44 \\
\hline Gpr50 & Melatonin-related receptor & 70.9 & 6.15 \\
\hline Itgad & Integrin alpha-D & 70.02 & 6.13 \\
\hline Prr32 & Proline-rich protein 32 & 64.88 & 6.02 \\
\hline Lipf & Gastric triacylglycerol lipase & 64.78 & 6.02 \\
\hline Kcnj14 & $\begin{array}{l}\text { ATP-sensitive inward rectifier } \\
\text { potassium channel } 14\end{array}$ & 59.97 & 5.91 \\
\hline Slc5a7 & $\begin{array}{l}\text { High affinity choline transporter } \\
1\end{array}$ & 52.39 & 5.71 \\
\hline Oxtr & Oxytocin receptor & 34.17 & 5.09 \\
\hline Il1rn & $\begin{array}{l}\text { Interleukin-1 receptor } \\
\text { antagonist }\end{array}$ & 32.82 & 5.04 \\
\hline Lep & Leptin & 27.20 & 4.77 \\
\hline$A d h 6 b$ & Alcohol dehydrogenase 6B & 21.42 & 4.42 \\
\hline Itgax & Integrin alpha-X & 17.95 & 4.17 \\
\hline Cdsn & Corneodesmosin & 16.81 & 4.07 \\
\hline Paqr9 & $\begin{array}{l}\text { Membrane progesterone } \\
\text { receptor epsilon }\end{array}$ & 13.39 & 3.74 \\
\hline Pnpla3 & $\begin{array}{l}\text { 1-acylglycerol-3-phosphate O- } \\
\text { acyltransferase }\end{array}$ & 13.09 & 3.71 \\
\hline$H p$ & Haptoblobin precursor & 11.55 & 3.53 \\
\hline Saa3 & Serum amyloid A-3 protein & 10.16 & 3.34 \\
\hline Dgat2 & $\begin{array}{l}\text { Diacylglycerol O- } \\
\text { acyltransferase } 2\end{array}$ & 10.34 & 3.37 \\
\hline Mest & $\begin{array}{l}\text { Mesoderm-specific transcript } \\
\text { protein }\end{array}$ & 9.83 & 3.30 \\
\hline Rgs1 & $\begin{array}{l}\text { Regulator of G-protein } \\
\text { signaling } 1\end{array}$ & 9.77 & 3.30 \\
\hline Wfdc21 & Protein Wfdc21 & 9.46 & 3.24 \\
\hline Fgf13 & Fibroblast growth factor 13 & 9.25 & 3.21 \\
\hline Atp6v0d2 & $\begin{array}{l}\text { V-type proton ATPase subunit } \\
\text { d } 2\end{array}$ & 7.96 & 3.00 \\
\hline Tenm4 & Teneurin-4 & 7.25 & 2.86 \\
\hline$I l 7 r$ & $\begin{array}{l}\text { Interleukin-7 receptor subunit } \\
\text { alpha }\end{array}$ & 7.16 & 2.84 \\
\hline S100a8 & $\begin{array}{l}\text { S100 calcium-binding protein } \\
\text { A8 }\end{array}$ & 6.92 & 2.79 \\
\hline $\begin{array}{c}\text { Downregulated } \\
\text { Gene }\end{array}$ & Protein name & $\begin{array}{l}\text { Fold } \\
\text { change }\end{array}$ & Log2Ratio \\
\hline
\end{tabular}

This article is protected by copyright. All rights reserved. 


\begin{tabular}{|c|l|c|c|}
\hline Mup2 & Major urinary protein 2 & 608 & -9.25 \\
\hline Mup11 & Major urinary protein 11 & 75.04 & -6.23 \\
\hline Acsm3 & Acyl-coenzyme A synthetase & 33.09 & -5.05 \\
\hline Mrgprg & $\begin{array}{l}\text { Mas-related G-protein coupled } \\
\text { receptor member G }\end{array}$ & 17.30 & -4.10 \\
\hline Mup14 & Major urinary protein 14 & 11.12 & -3.48 \\
\hline Cxcl13 & C-X-C motif chemokine 13 & 10.94 & -3.45 \\
\hline Fosb & Protein fosB & 7.79 & -2.96 \\
\hline
\end{tabular}

Table 3 The 35 most enriched genes in WT HFD relative to WT controls.

This article is protected by copyright. All rights reserved. 


\begin{tabular}{|c|c|c|}
\hline $\begin{array}{l}\text { Immune } \\
\text { mediated } \\
\text { KEGG } \\
\text { Pathways }\end{array}$ & p-value & Enriched Genes \\
\hline $\begin{array}{l}\text { Antigen } \\
\text { processing and } \\
\text { presentation }\end{array}$ & $6.5 \mathrm{E}-4$ & Ctsb|Ctsl|H2-K1|H2-Ab1|H2-Aa|H2-Eb1|Cd74 \\
\hline $\begin{array}{l}\text { B cell receptor } \\
\text { signaling } \\
\text { pathway }\end{array}$ & 0.0303 & Rac2|Pik3ap1|Blnk|Lilrb3 \\
\hline $\begin{array}{l}\text { Chemokine } \\
\text { signalling } \\
\text { pathway }\end{array}$ & 0.044 & Ccl8|Ccl6|Ccl9|Rac2|Ccr5|Adcy5 \\
\hline $\begin{array}{l}\text { Natural killer cell } \\
\text { mediated } \\
\text { cytotoxicity }\end{array}$ & 0.0295 & Itgb2|H2-K1|Tyrobp|Rac2|Fcer1g \\
\hline $\begin{array}{l}\text { Complement and } \\
\text { coagulation } \\
\text { cascades }\end{array}$ & 0.016 & Itgb2 $|C f b| C 1 q c \mid$ Serpine $1 \mid C 1 q b$ \\
\hline $\begin{array}{l}\text { Immune } \\
\text { mediated } \\
\text { Process }\end{array}$ & p-value & Enriched Genes \\
\hline $\begin{array}{l}\text { Leukocyte } \\
\text { activation }\end{array}$ & $8.53 E-6$ & $\begin{array}{l}\text { Itgb2|Sfpi1 } \mid \text { Lbp } \mid \text { Mfng } \mid \text { Cd180|Dock8|Hprt|Slc11a1 } \\
\text { Clec4a2|Tyrobp } \mid \text { H2-Ab1|Blnk|Lilrb3|Fcer1g|Myo1f } \\
\text { Cd74|Selplg|Lcp1|Fcgr3 }\end{array}$ \\
\hline Phagocytosis & $6.1 \mathrm{E}-4$ & Itgb2|Lbp|Trem2|Slc11a1|Fcer1g|Iglc2|Arhgap25|Fcgr3 \\
\hline Defense response & $3.16 \mathrm{E}-8$ & $\begin{array}{l}\text { Itgb2|Ccl8|Lbp } \mid \text { Cyba|Ccl6|Ccl9|Evl|Ly86|Cd180|Trem2 } \\
\mid \text { H2-K1|Cfb|Slc11a1|Tfr2|Clec4a2|Cotl1|C1qc|Serpine1 } \\
\text { C1qb|H2-Ab1|H2-Aa|Ffar2|Lipa|Ptafr } \mid \text { Alox5ap } \mid \text { Fcer1g } \\
\text { Myo1f|Hfe } \mid \text { Lyz2 } \mid \text { Cd74|Cd37|Iglc2|Ccr5|Unc93b1|Fcgr3 }\end{array}$ \\
\hline $\begin{array}{l}\text { Regulation of } \\
\text { cytokine } \\
\text { production }\end{array}$ & $1.6 \mathrm{E}-5$ & $\begin{array}{l}\text { Lbp } \mid \text { Cyba|Dies1|Ankrd2|Slc11a1|Clec4a2|Nckap1l|Tspo } \\
\text { Serpine1|Inhbb|Cd300ld|Ffar2|Ptafr|Postn|Fcer1g|Hfe } \\
\text { AF251705|Cd74|Ccr5|Unc93b1|Fcgr3 }\end{array}$ \\
\hline $\begin{array}{l}\text { Inflammatory } \\
\text { response }\end{array}$ & $2.38 \mathrm{E}-5$ & $\begin{array}{l}\text { Itgb2|Ccl8|Lbp|Cyba|Ccl6|Ccl9|Ly86|Cd180|Slc11a1 } \\
\text { Tfr2|Ffar2|Lipa|Ptafr|Alox5ap|Fcer1g|Hfe|Ccr5|Fcgr3 }\end{array}$ \\
\hline $\begin{array}{l}\text { B cell mediated } \\
\text { immunity }\end{array}$ & $4.94 \mathrm{E}-5$ & C1qc|C1qb|H2-Ab1|Lilrb3|Fcer1g|Cd74|Iglc2|Fcgr3 \\
\hline Chemotaxis & 0.0015 & $\begin{array}{l}\text { Itgb2 } \mid \text { Ccl8 } \mid \text { Lbp } \mid \text { Ccl6 } \mid \text { Ccl9|Evl|Alcam } \mid \text { Nckap1l|Rac2 } \\
\text { Ffar2|Ptafr } \mid \text { Fcer1g } \mid \text { Ccr5|Fcgr3 }\end{array}$ \\
\hline
\end{tabular}

Table 4 KEGG pathways and processes with enriched immune-related genes found to be differentially expressed in sciatic nerves from SC-p $75^{\mathrm{NTR}}$-KO HFD mice but not in those from WT HFD animals.

This article is protected by copyright. All rights reserved. 


\begin{tabular}{|c|c|c|}
\hline $\begin{array}{l}\text { KEGG } \\
\text { Pathway }\end{array}$ & p-value & Enriched Genes \\
\hline Lysosome & $3.45 \mathrm{E}-5$ & Ctsb|Ctsk|Npc2|Ctsl|Gusb|Slc11a1|Man2b1|Lipa|Cd68|Laptm5 \\
\hline Phagosome & $8.1 \mathrm{E}-4$ & $\begin{array}{l}\text { Itgb2|Cyba|Ctsl|H2-K1|H2-Ab1|H2-Aa| } \\
\text { H2-Eb1|Mrc2|Fcgr3 }\end{array}$ \\
\hline $\begin{array}{l}\text { Cholesterol } \\
\text { metabolism }\end{array}$ & 0.002 & Angptl4|Npc2|Tspo|Lipa|Pltp \\
\hline Peroxisome & 0.0025 & Acaa1b|Hsd17b4|Prdx5|Pex16|Acox1|Abcd2 \\
\hline $\begin{array}{l}\text { Cell adhesion } \\
\text { molecules } \\
\text { (CAMs) }\end{array}$ & 0.0092 & Itgb2|Alcam|H2-K1|H2-Ab1|H2-Aa|H2-Eb1|Selplg \\
\hline
\end{tabular}

Table 5 Differential enriched KEGG pathways in the SC-p75 ${ }^{\mathrm{NTR}}-\mathrm{KO}$ with HFD (non-immune related) versus SC-p $75^{\mathrm{NTR}}$-KO counterparts. These pathways were not found to be activated by HFD in WT mice.

This article is protected by copyright. All rights reserved. 


\begin{tabular}{|c|l|c|c|}
\hline Gene & \multicolumn{1}{|c|}{ Protein name } & Probability & Fold change \\
\hline Ctsb & Cathepsin B & 0.85 & 2.63 \\
\hline Ctsk & Cathepsin K & 0.81 & 2.08 \\
\hline Ctsl & Cathepsin L & 0.83 & 2.18 \\
\hline Ctss & Cathepsin S & 0.88 & 3.88 \\
\hline Npc2 & $\begin{array}{l}\text { Intracellular cholesterol } \\
\text { transporter 2 }\end{array}$ & 0.83 & 2.22 \\
\hline Gusb & Beta-Glucuronidase & 0.82 & 2.52 \\
\hline Slc11a1 & $\begin{array}{l}\text { Natural resistance-associated } \\
\text { macrophage protein 1 }\end{array}$ & 0.81 & 2.74 \\
\hline Man2b1 & Lysosomal alpha-mannosidase & 0.82 & 2.51 \\
\hline Lipa & Lysosomal acid lipase & 0.83 & 2.36 \\
\hline Cd68 & Macrosialin & 0.88 & 3.83 \\
\hline Laptm5 & $\begin{array}{l}\text { Lysosomal-associated } \\
\text { transmembrane protein 5 }\end{array}$ & 0.83 & 2.46 \\
\hline
\end{tabular}

Table 6 Enriched genes related to the Lysosome KEGG Pathway, upregulated only in nerves from SC-p $75^{\text {NTR }}$-KO mice with HFD, as compared with WT HFD.

This article is protected by copyright. All rights reserved. 
(a)

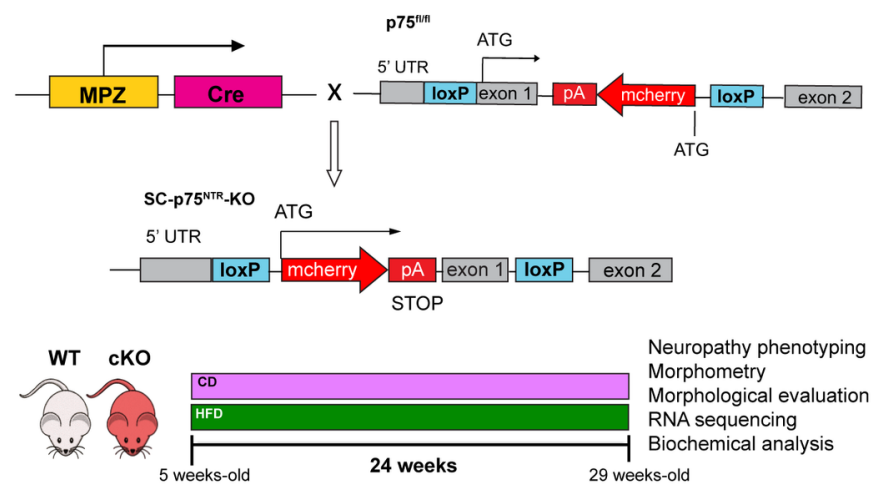

(c)

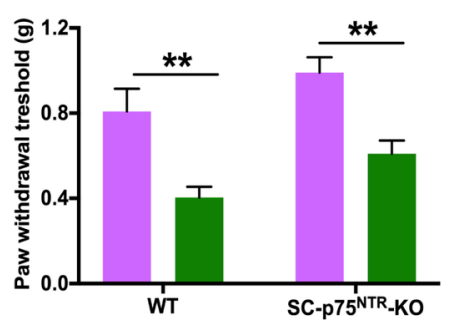

(b)

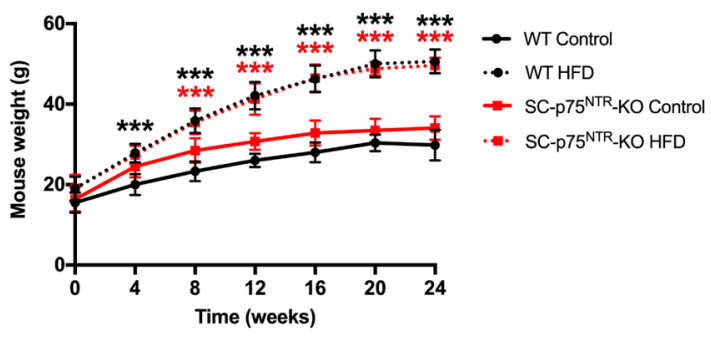

(e)

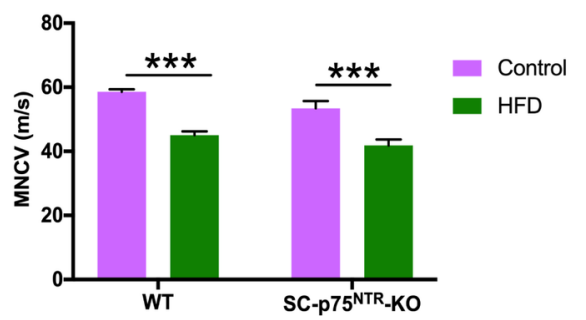

GLIA_23881_Figure 1.tif 
(a)

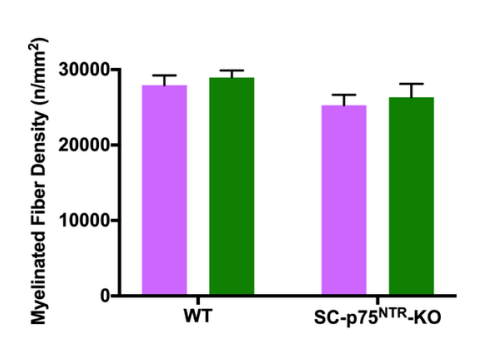

(b)

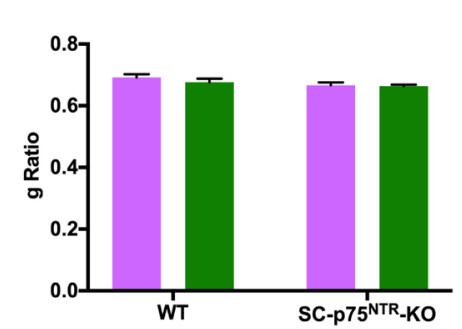

(c)

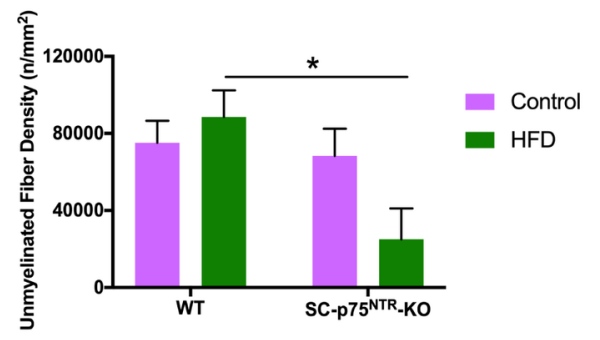

(d)
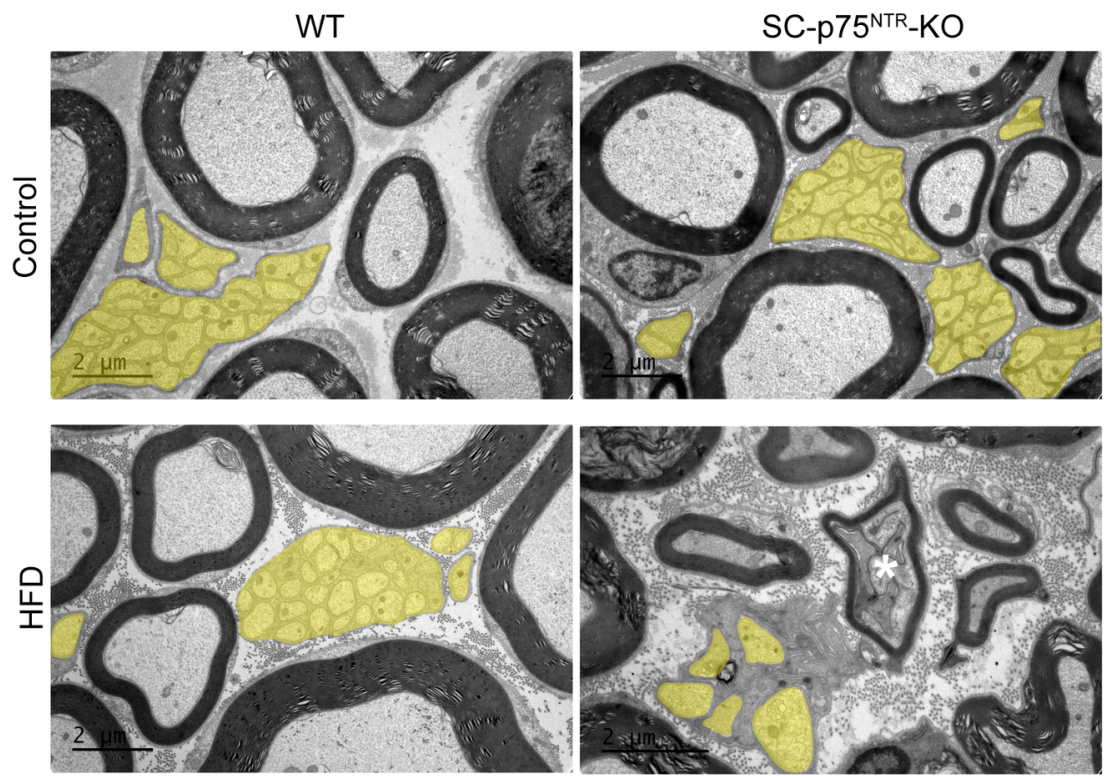

GLIA_23881_Figure 2.tif

This article is protected by copyright. All rights reserved. 
(a)

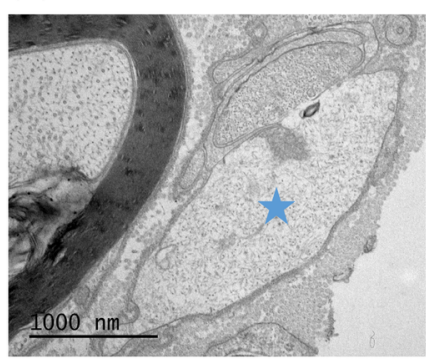

(b)

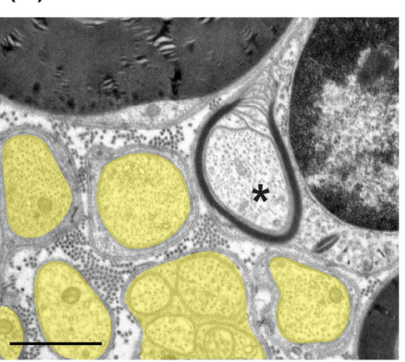

(c)

(d)

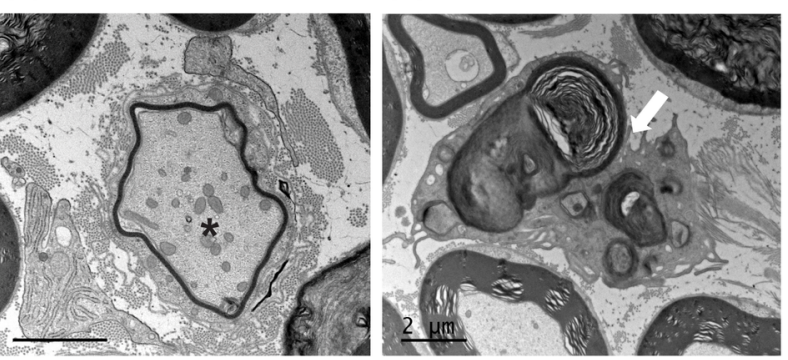

(e)

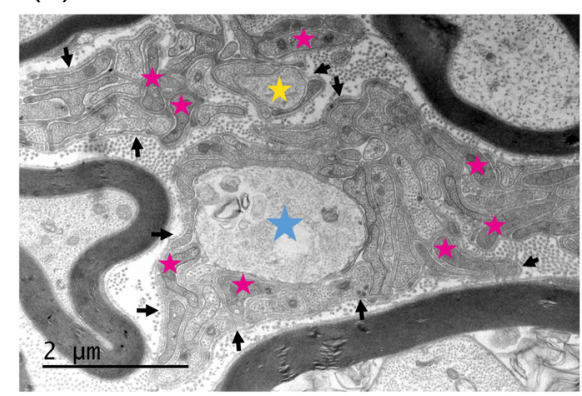

(f)

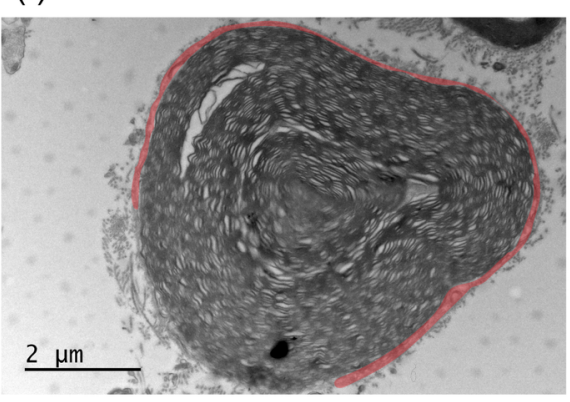

(g)

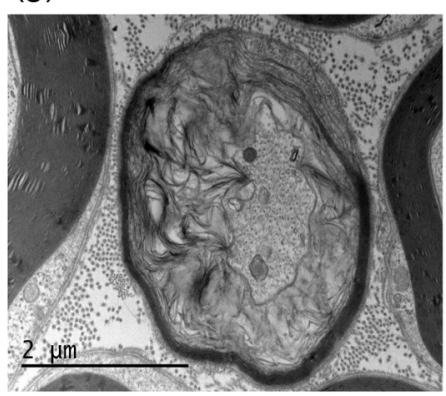

(h)

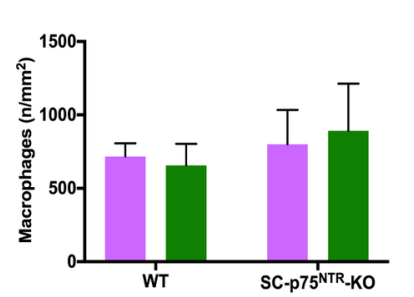

(i)

(j)
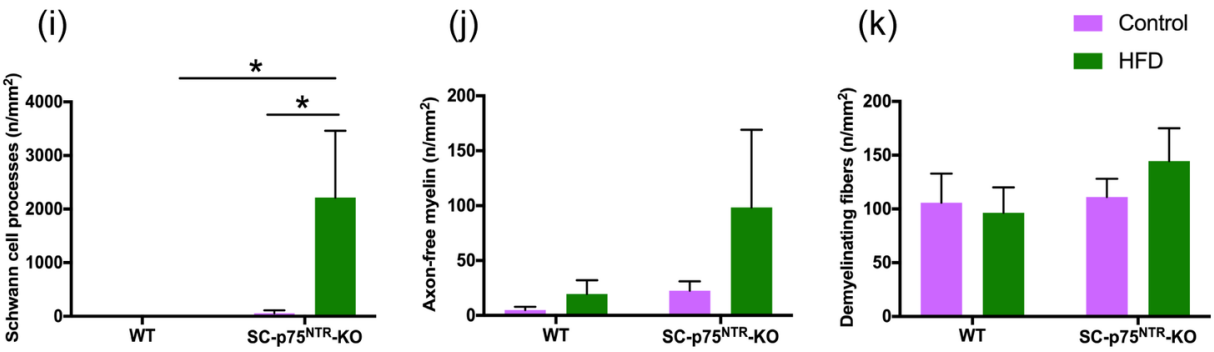

GLIA_23881_Figure 3.tif 
(a)

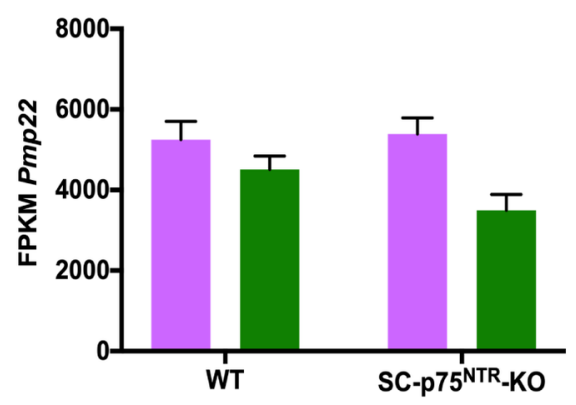

(c)

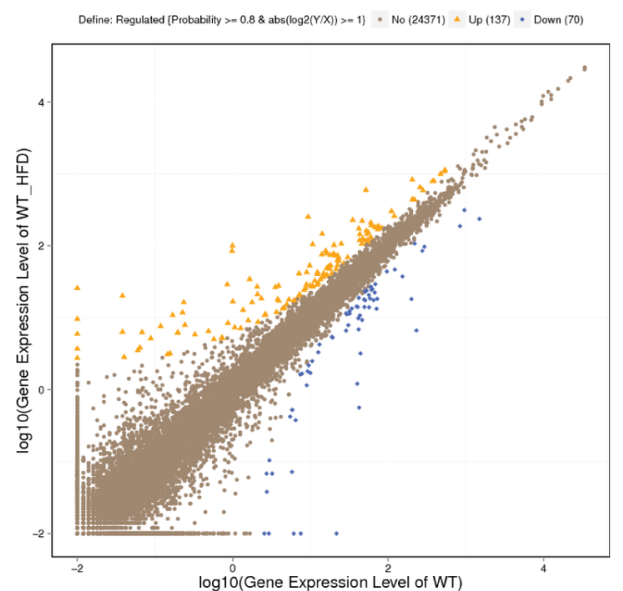

(b)

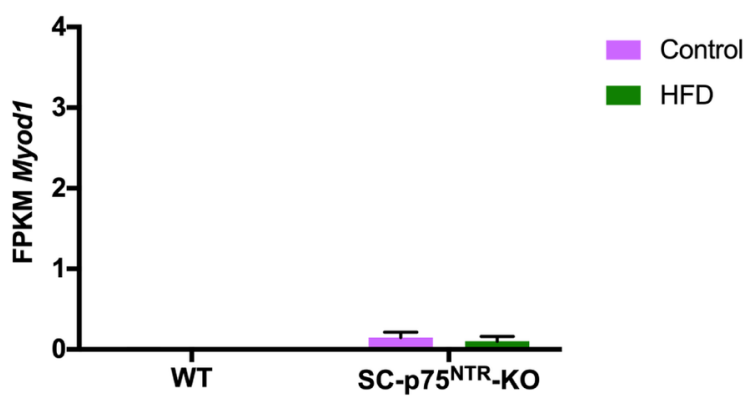

(d)

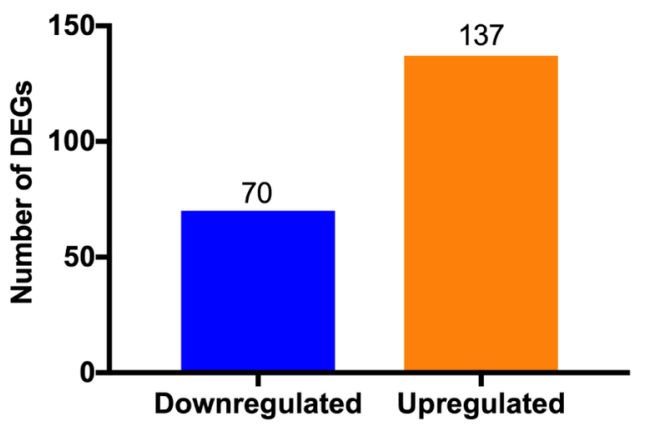

WT VS WT HFD

(e)

\section{WT VS WT HFD}

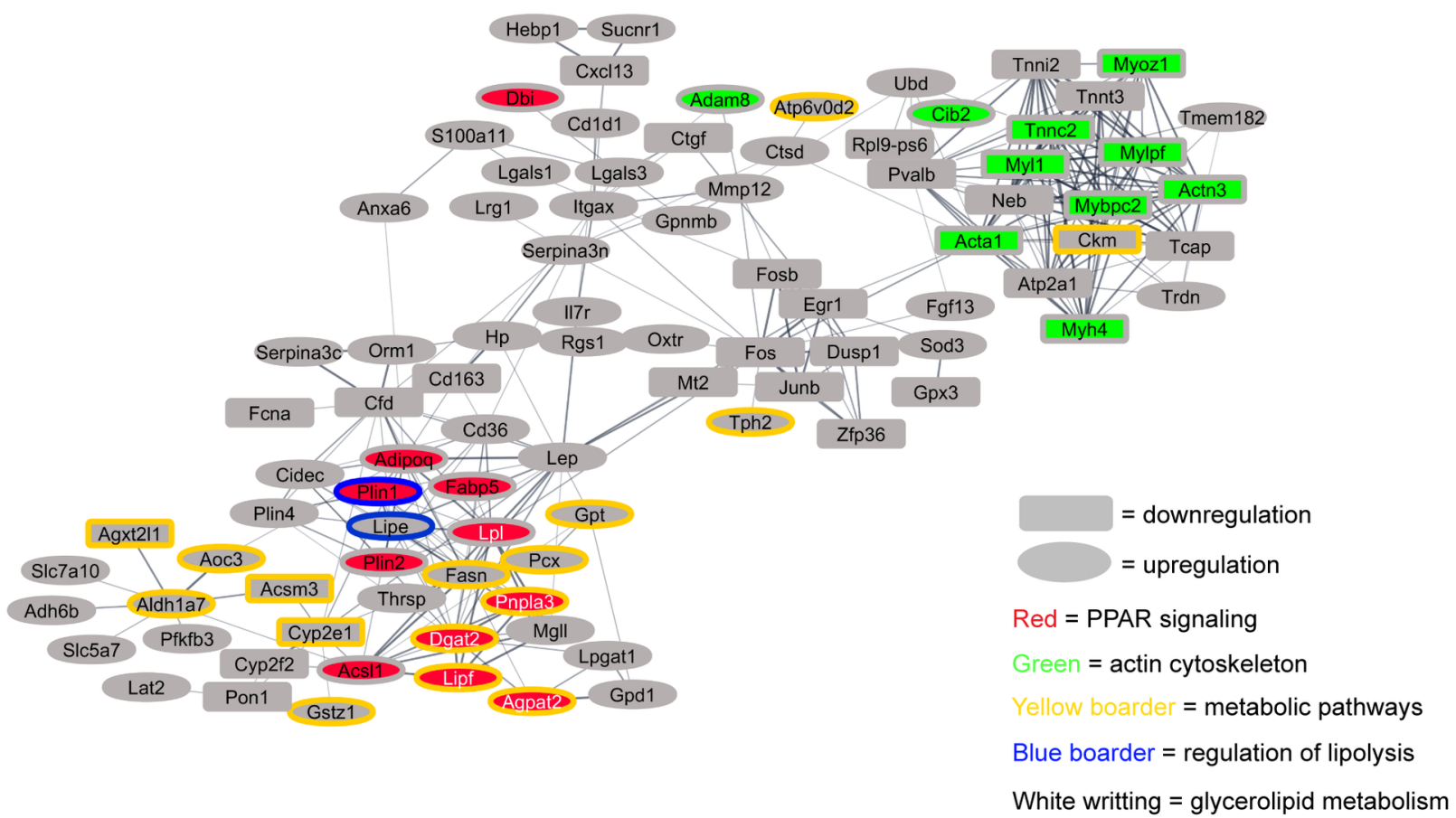

GLIA_23881_Figure 4.tif

This article is protected by copyright. All rights reserved. 
(a)
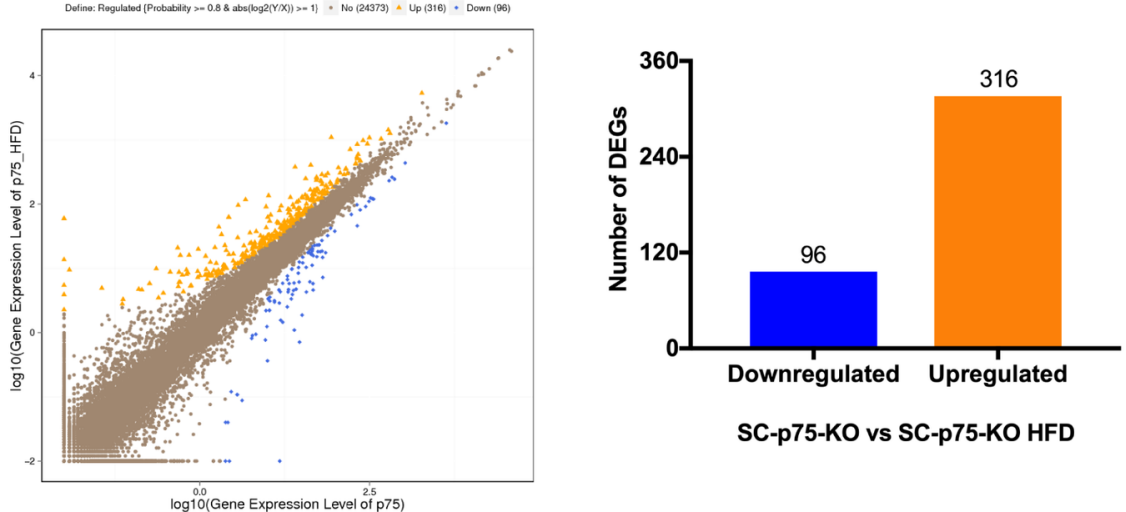

(d)

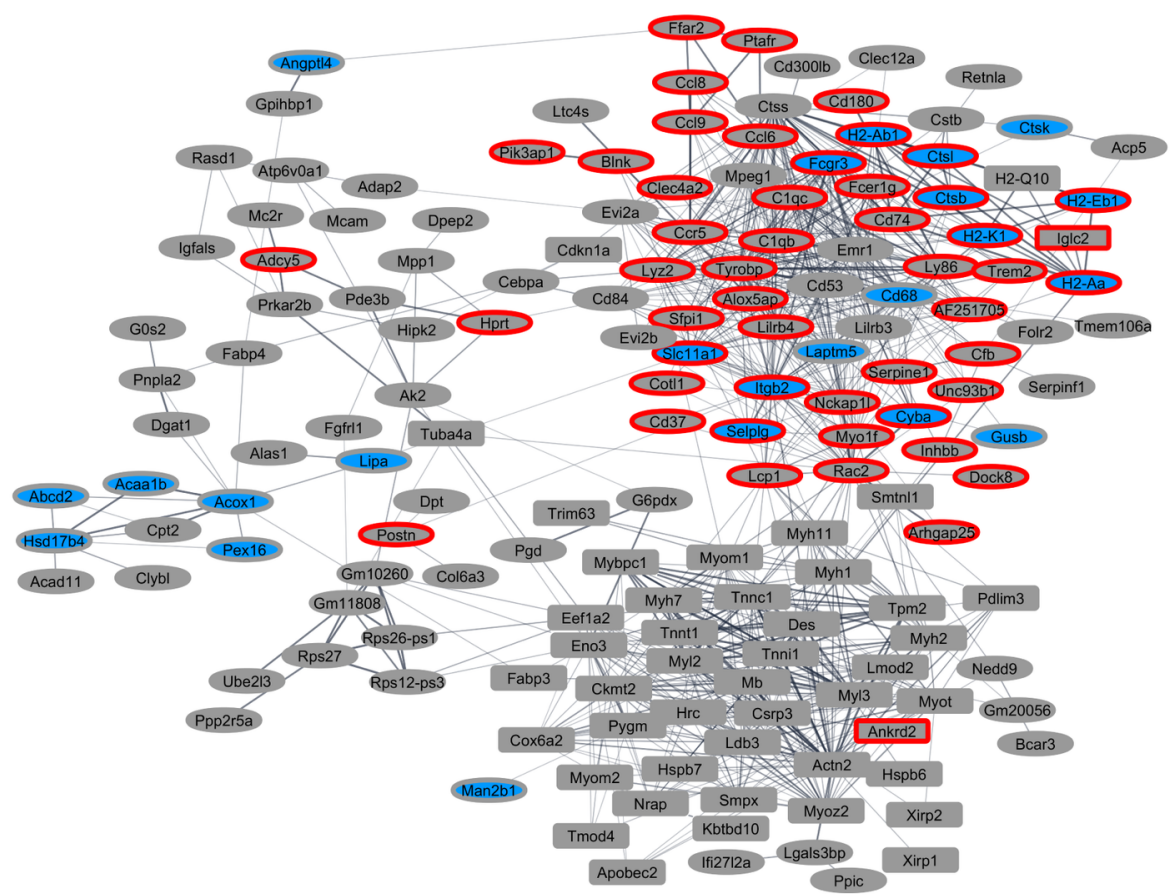

(e)

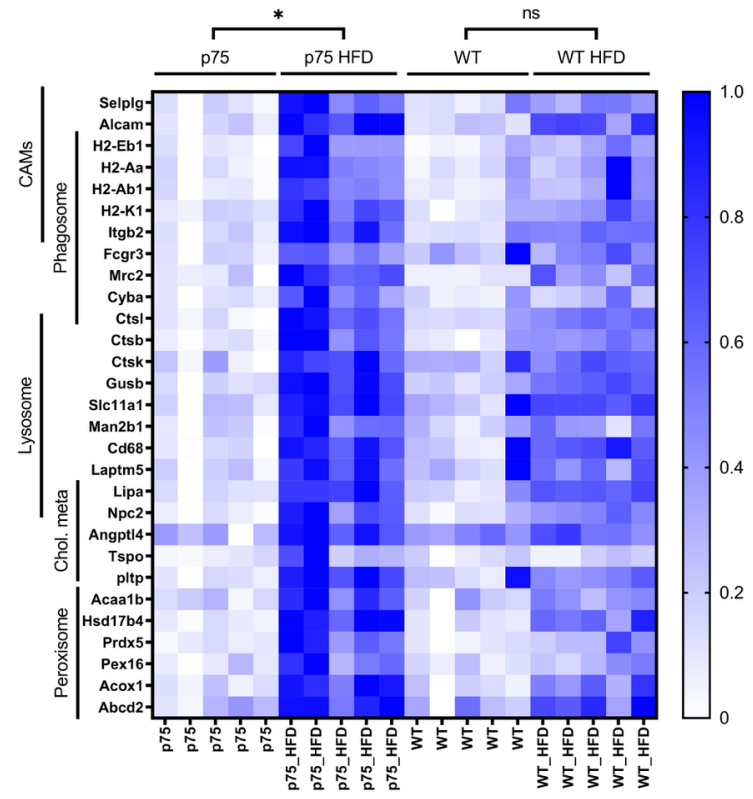

GLIA_23881_Figure 5.tif (c)

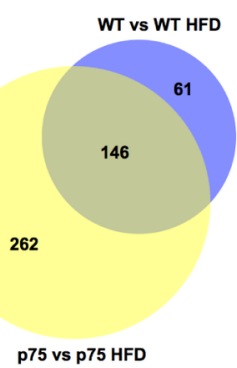

$=$ downregulation = upregulation

Red $=$ immune-related genes Blue $=$ cell adhesion, cholesterol, phagosome, lysosome, peroxisome pathways

This article is protected by copyright. All rights reserved. 
(a)

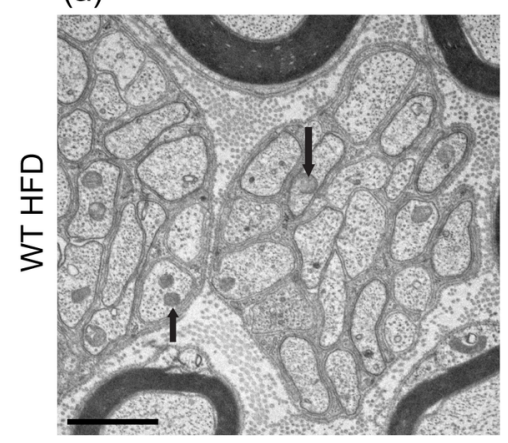

(c)

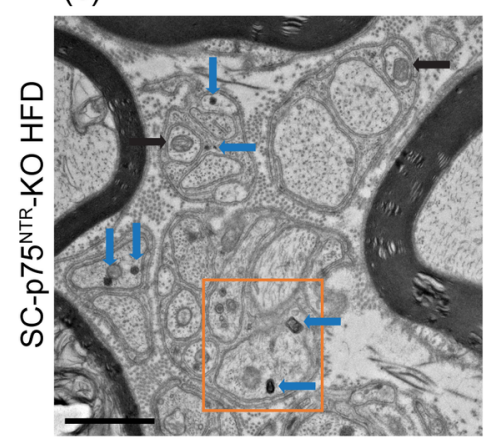

(g)

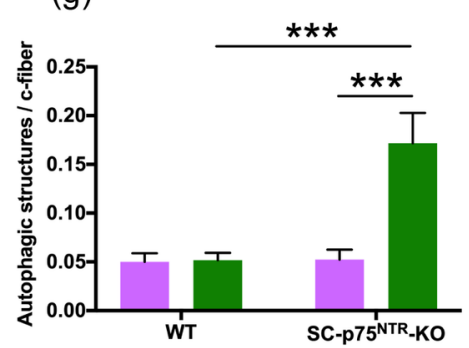

(j)

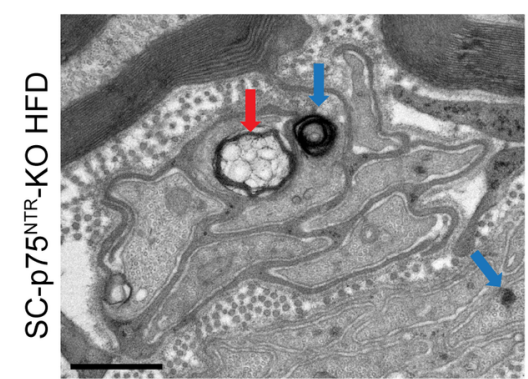

(I)

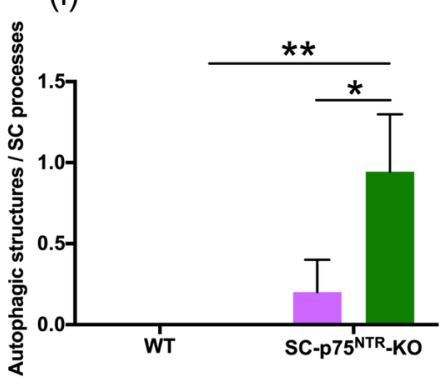

(b)

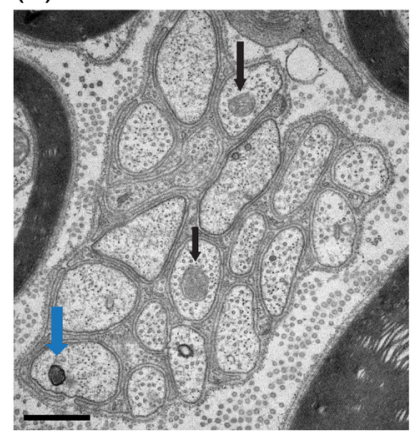

(d)

(e)

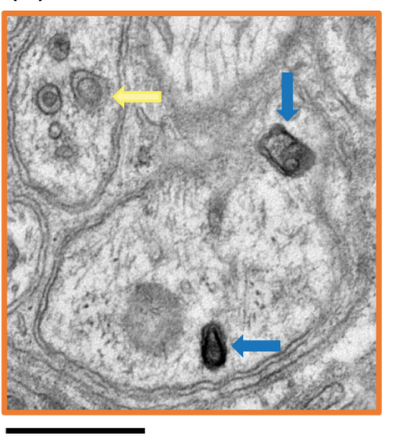

(h)

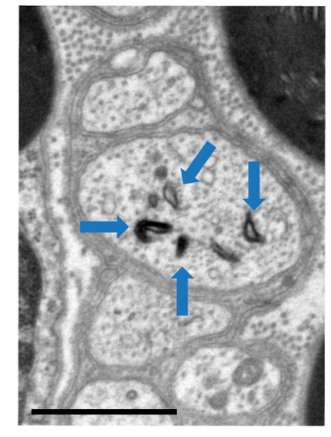

(f)

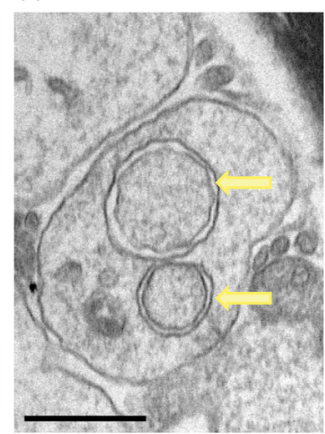

(i)
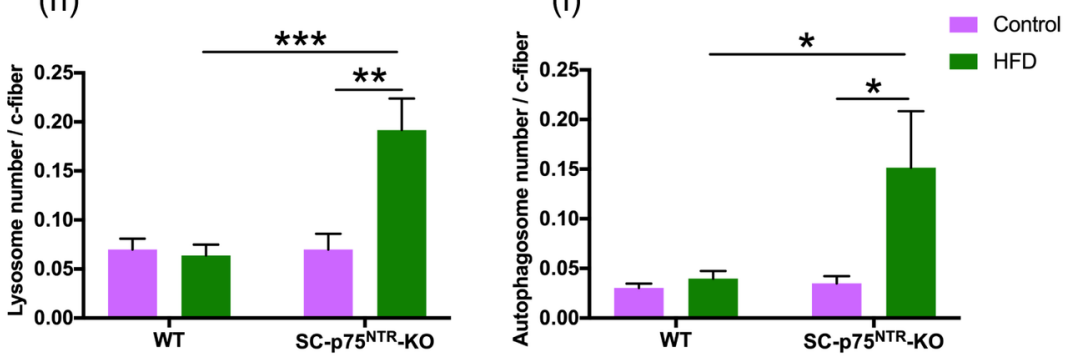

(k)

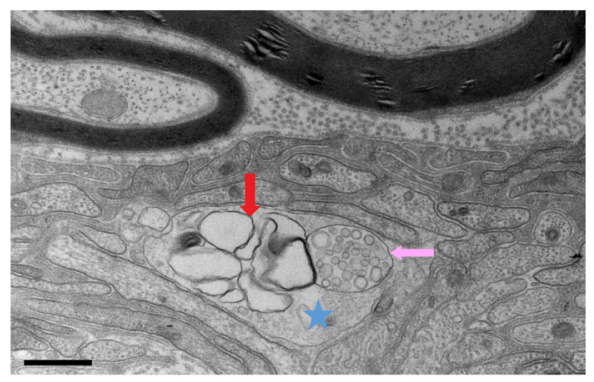

(m)
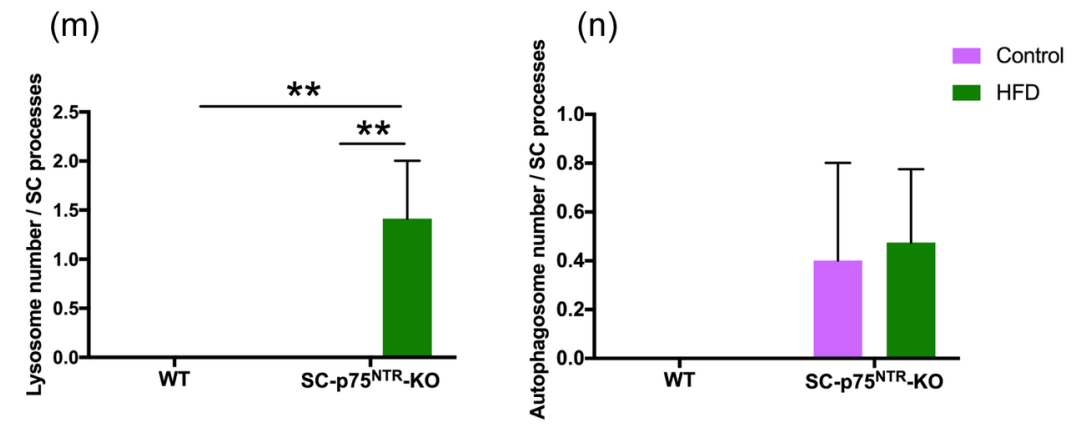

GLIA_23881_Figure 6.tif

This article is protected by copyright. All rights reserved. 
(a)
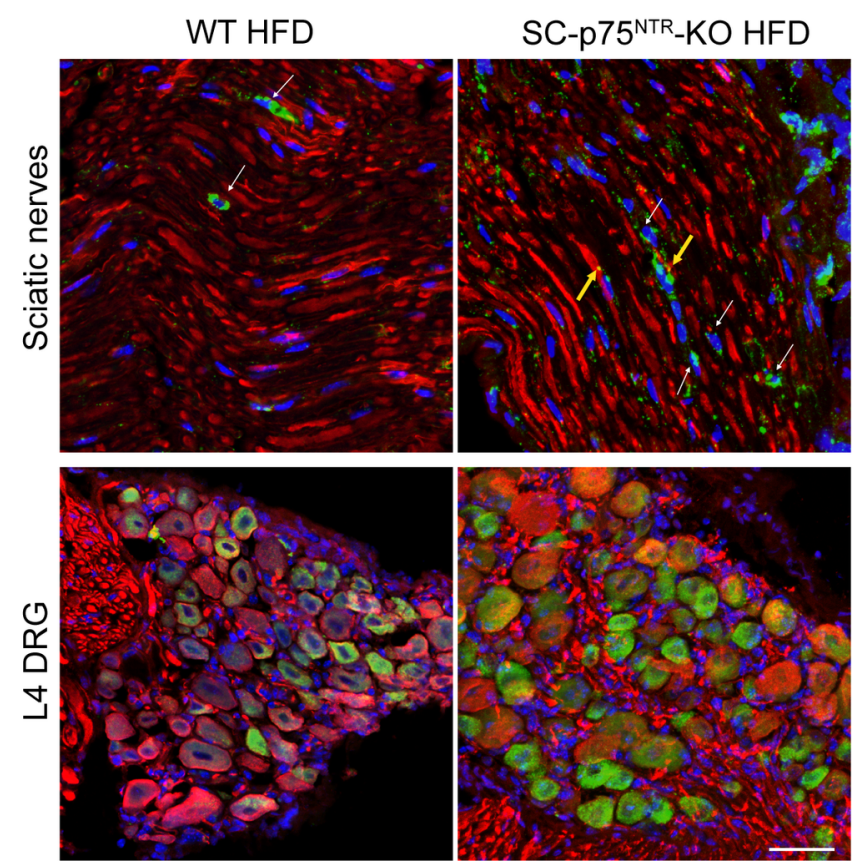

(b)
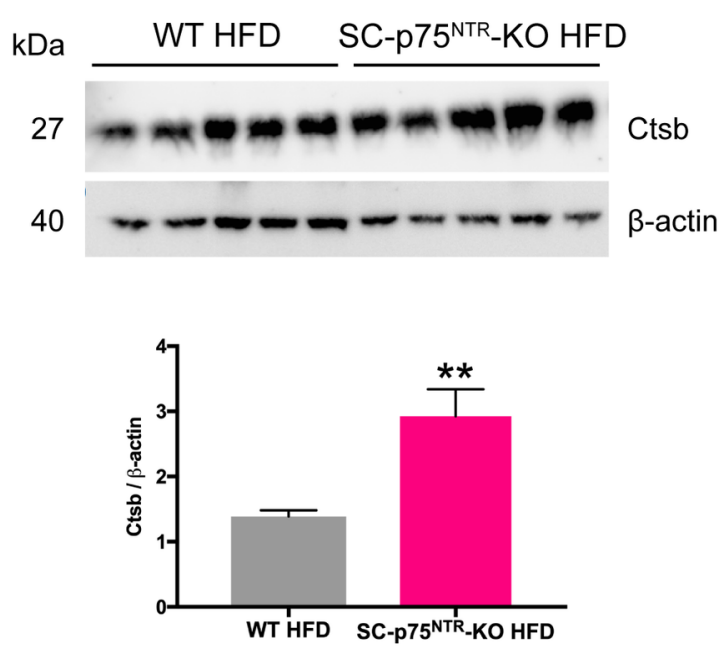

Lumbar DRGs

GLIA_23881_Figure 7.tif 


\begin{tabular}{|c|c|c|}
\hline Upregulated & p-value & Enriched Genes \\
\hline $\begin{array}{l}\text { PPAR signaling } \\
\text { pathway }\end{array}$ & $4.32 \mathrm{E}-5$ & Plin2|Lpl|Adipoq|Fabp5|Aqp7|Plin1|Acsl1|Dbi \\
\hline $\begin{array}{l}\text { Glycerolipid } \\
\text { metabolism }\end{array}$ & 0.0045 & Lpl|Lipf|Agpat2|Dgat2|Pnpla3 \\
\hline $\begin{array}{l}\text { Regulation of } \\
\text { lipolysis }\end{array}$ & 0.0045 & Lipe $\mid$ Tshr $\mid$ Aqp7|Plin1|Ptger3 \\
\hline $\begin{array}{l}\text { Metabolic } \\
\text { pathways }\end{array}$ & 0.0341 & $\begin{array}{l}\text { Ckm|Tph2|Galntl2|Gpt|Aldh1a7|Lipf|Cyp2e1| } \\
\text { Agpat2|Atp6v0d2|Dgat2|Prps1|Acsl1|Nnmt|Pnpla3|Fasn } \mid \\
\text { Gstz1|Pcx } \mid \text { Acsm3|Agxt2l1|Aoc3 }\end{array}$ \\
\hline Downregulated & p-value & Enriched Genes \\
\hline $\begin{array}{l}\text { Actin } \\
\text { Cytoskeleton }\end{array}$ & 0.006 & $\begin{array}{l}\text { Actn3|Myh4|Myl1|Mylpf|Acta1|Cib2|Myoz1|Tnnc2|Adam8 } \\
\text { Synpo2|Mybpc2 }\end{array}$ \\
\hline
\end{tabular}

Table 1 Upregulated KEGG pathways in the WT HFD versus WT counterparts.

Most of the downregulated genes belong to the actin cytoskeleton component. 


\begin{tabular}{|c|c|c|}
\hline $\begin{array}{l}\text { Immune } \\
\text { mediated process }\end{array}$ & p-value & Enriched Genes \\
\hline $\begin{array}{l}\text { Response to } \\
\text { Cytokine }\end{array}$ & $5.6 \mathrm{E}-4$ & $\begin{array}{l}\text { Il7r } \mid \text { Saa3 } \mid \text { Serpina3n } \mid \text { Fos } \mid \text { Adipoq } \mid \text { Gpd1 } \mid \text { Cxcl13 } \mid \text { Acsl1 } \mid \\
\text { Ubd } \mid \text { Oxtr } \mid \text { Fasn } \mid \text { Zfp36 } \mid \text { Ifi205 } \mid \text { Wdnm1-like } \mid \text { Junb } \mid \\
\text { Lep } \mid \text { Egr1 } \mid \text { Serpina3c|Il1rn }\end{array}$ \\
\hline $\begin{array}{l}\text { Acute phase } \\
\text { response }\end{array}$ & $1.79 \mathrm{E}-5$ & Saa3|Serpina3n $\mid$ Orm1| Ptger3|Hp|Cd163|Il1rn \\
\hline $\begin{array}{l}\text { Inflammatory } \\
\text { response }\end{array}$ & 0.0056 & $\begin{array}{l}\text { Adipoq|Sucnr1|Ptger3|Zfp36|S100a8|Lep|Aoc3|Adam8|Saa3 } \\
\text { Serpina3n|Cela1|Cxcl13|Orm1|Hp|Cd163|Il1rn }\end{array}$ \\
\hline $\begin{array}{l}\text { Leucocyte } \\
\text { differentiation }\end{array}$ & 0.0026 & $\begin{array}{l}\text { Il7r|Tshr|Fam20c|Cd1d1|Ubd|Fasn|Junb|Lep|Egr1|Lgals1| } \\
\text { Adam8 }\end{array}$ \\
\hline $\begin{array}{l}\text { Regulation of } \\
\text { cytokine } \\
\text { production }\end{array}$ & 0.0306 & $\begin{array}{l}\text { Mmp12|Lpl|Adipoq|Agpat2|Fcna } \mid \text { Cd1d1| } \\
\text { Errfi1|Gpnmb } \mid \text { Zfp36|Lep } \mid \text { Egr1|Adam8 }\end{array}$ \\
\hline Cell chemotaxis & 0.0363 & Saa3|Cxcl14|Cxcl13|S100a8|Adam8|Lgals3 \\
\hline Defense response & 0.0102 & $\begin{array}{l}\text { Saa3 } \mid \text { Serpina3n } \mid \text { Cela1 } \mid \text { Cxcl13 } \mid \text { Fcna } \mid \text { Cd1d1| } \\
\text { Orm1 } \mid \text { Itgax } \mid \text { Ubd } \mid \text { Ptger3 } \mid \text { Cfd } \mid \text { S100a8 } \mid \\
\text { Hp } \mid \text { Aoc3 } \mid \text { Adam8 } \mid \text { Cd163 } \mid \text { Il1rn } \mid \text { Lgals3 } \mid \text { Dbi }\end{array}$ \\
\hline $\begin{array}{l}\text { Regulation of } \mathrm{T} \\
\text { cell apoptotic } \\
\text { process }\end{array}$ & 0.0114 & Il7r|Adam8|Tsc22d3|Lgals3 \\
\hline $\begin{array}{l}\text { Leukocyte } \\
\text { activation }\end{array}$ & 0.0391 & $\begin{array}{l}\text { Il7r|Tshr|Sucnr1 } \mid \text { Cd1d1|Itgad } \mid \text { Ubd } \mid \text { Lat2 } \mid \\
\text { Lep } \mid \text { Egr1 } \mid \text { Lgals1 }\end{array}$ \\
\hline $\begin{array}{l}\text { Toll-like receptor } \\
4 \text { binding }\end{array}$ & 0.0392 & Saa3|S100a8 \\
\hline $\begin{array}{l}\text { Leukocyte } \\
\text { migration }\end{array}$ & 0.0423 & S100a8 |Cxcl13|Aoc3|Adam8|Lgals3|Lep \\
\hline $\begin{array}{l}\text { Regulation of } \\
\text { tumor necrosis } \\
\text { factor production }\end{array}$ & 0.0474 & Adipoq|Errfi1|Gpnmb|Zfp36|Lep \\
\hline
\end{tabular}

Table 2 Immune system related processes differentially regulated in the WT HFD, as compared to WT mice feed with the control diet. 


\begin{tabular}{|c|c|c|c|}
\hline $\begin{array}{l}\text { Upregulated } \\
\text { Gene }\end{array}$ & Protein name & $\begin{array}{c}\text { Fold } \\
\text { change }\end{array}$ & Log2Ratio \\
\hline Tph2 & Tryptophan 5-hydroxylase 2 & 530.95 & 9.052 \\
\hline Mmp12 & Matrix metalloproteinase 12 & 101.51 & 6.67 \\
\hline Ubd & Ubiquitin D & 86.74 & 6.44 \\
\hline Gpr50 & Melatonin-related receptor & 70.9 & 6.15 \\
\hline Itgad & Integrin alpha-D & 70.02 & 6.13 \\
\hline Prr32 & Proline-rich protein 32 & 64.88 & 6.02 \\
\hline Lipf & Gastric triacylglycerol lipase & 64.78 & 6.02 \\
\hline Kcnj14 & $\begin{array}{l}\text { ATP-sensitive inward rectifier } \\
\text { potassium channel } 14\end{array}$ & 59.97 & 5.91 \\
\hline Slc5a7 & $\begin{array}{l}\text { High affinity choline transporter } \\
1\end{array}$ & 52.39 & 5.71 \\
\hline Oxtr & Oxytocin receptor & 34.17 & 5.09 \\
\hline Il1rn & $\begin{array}{l}\text { Interleukin-1 receptor } \\
\text { antagonist }\end{array}$ & 32.82 & 5.04 \\
\hline Lep & Leptin & 27.20 & 4.77 \\
\hline$A d h 6 b$ & Alcohol dehydrogenase 6B & 21.42 & 4.42 \\
\hline Itgax & Integrin alpha-X & 17.95 & 4.17 \\
\hline Cdsn & Corneodesmosin & 16.81 & 4.07 \\
\hline Paqr9 & $\begin{array}{l}\text { Membrane progesterone } \\
\text { receptor epsilon }\end{array}$ & 13.39 & 3.74 \\
\hline Pnpla3 & $\begin{array}{l}\text { 1-acylglycerol-3-phosphate O- } \\
\text { acyltransferase }\end{array}$ & 13.09 & 3.71 \\
\hline$H p$ & Haptoblobin precursor & 11.55 & 3.53 \\
\hline Saa3 & Serum amyloid A-3 protein & 10.16 & 3.34 \\
\hline Dgat2 & $\begin{array}{l}\text { Diacylglycerol O- } \\
\text { acyltransferase } 2\end{array}$ & 10.34 & 3.37 \\
\hline Mest & $\begin{array}{l}\text { Mesoderm-specific transcript } \\
\text { protein }\end{array}$ & 9.83 & 3.30 \\
\hline Rgs1 & $\begin{array}{l}\text { Regulator of G-protein } \\
\text { signaling } 1\end{array}$ & 9.77 & 3.30 \\
\hline$W f d c 21$ & Protein Wfdc21 & 9.46 & 3.24 \\
\hline Fgf13 & Fibroblast growth factor 13 & 9.25 & 3.21 \\
\hline Atp6v0d2 & $\begin{array}{l}\text { V-type proton ATPase subunit } \\
\text { d } 2\end{array}$ & 7.96 & 3.00 \\
\hline Tenm4 & Teneurin-4 & 7.25 & 2.86 \\
\hline$I l 7 r$ & $\begin{array}{l}\text { Interleukin-7 receptor subunit } \\
\text { alpha }\end{array}$ & 7.16 & 2.84 \\
\hline S100a8 & $\begin{array}{l}\text { S100 calcium-binding protein } \\
\text { A8 }\end{array}$ & 6.92 & 2.79 \\
\hline $\begin{array}{l}\text { Downregulated } \\
\text { Gene }\end{array}$ & Protein name & $\begin{array}{c}\text { Fold } \\
\text { change }\end{array}$ & Log2Ratio \\
\hline Mup2 & Major urinary protein 2 & 608 & -9.25 \\
\hline Mup11 & Major urinary protein 11 & 75.04 & -6.23 \\
\hline Acsm3 & Acyl-coenzyme A synthetase & 33.09 & -5.05 \\
\hline
\end{tabular}

This article is protected by copyright. All rights reserved. 


\begin{tabular}{|c|l|c|c|}
\hline Mrgprg & $\begin{array}{l}\text { Mas-related G-protein coupled } \\
\text { receptor member G }\end{array}$ & 17.30 & -4.10 \\
\hline Mup14 & Major urinary protein 14 & 11.12 & -3.48 \\
\hline Cxcl13 & C-X-C motif chemokine 13 & 10.94 & -3.45 \\
\hline Fosb & Protein fosB & 7.79 & -2.96 \\
\hline
\end{tabular}

Table 3 The 35 most enriched genes in WT HFD relative to WT controls. 


\begin{tabular}{|c|c|c|}
\hline $\begin{array}{l}\text { Immune } \\
\text { mediated } \\
\text { KEGG } \\
\text { Pathways }\end{array}$ & p-value & Enriched Genes \\
\hline $\begin{array}{l}\text { Antigen } \\
\text { processing and } \\
\text { presentation }\end{array}$ & $6.5 \mathrm{E}-4$ & Ctsb|Ctsl|H2-K1|H2-Ab1|H2-Aa|H2-Eb1|Cd74 \\
\hline $\begin{array}{l}\text { B cell receptor } \\
\text { signaling } \\
\text { pathway }\end{array}$ & 0.0303 & Rac2|Pik3ap1|Blnk|Lilrb3 \\
\hline $\begin{array}{l}\text { Chemokine } \\
\text { signalling } \\
\text { pathway }\end{array}$ & 0.044 & Ccl8|Ccl6|Ccl9|Rac2|Ccr5|Adcy5 \\
\hline $\begin{array}{l}\text { Natural killer cell } \\
\text { mediated } \\
\text { cytotoxicity }\end{array}$ & 0.0295 & Itgb2|H2-K1|Tyrobp|Rac2|Fcer1g \\
\hline $\begin{array}{l}\text { Complement and } \\
\text { coagulation } \\
\text { cascades }\end{array}$ & 0.016 & Itgb2 $|C f b| C 1 q c \mid$ Serpine $1 \mid C 1 q b$ \\
\hline $\begin{array}{l}\text { Immune } \\
\text { mediated } \\
\text { Process }\end{array}$ & p-value & Enriched Genes \\
\hline $\begin{array}{l}\text { Leukocyte } \\
\text { activation }\end{array}$ & 8.53E-6 & $\begin{array}{l}\text { Itgb2|Sfpi1|Lbp } \mid \text { Mfng } \mid \text { Cd180|Dock8 } \mid \text { Hprt } \mid \text { Slc11a1 } \\
\text { Clec4a2|Tyrobp } \mid \text { H2-Ab1|Blnk|Lilrb3|Fcer1g|Myo1f } \\
\text { Cd74|Selplg|Lcp1|Fcgr3 }\end{array}$ \\
\hline Phagocytosis & $6.1 \mathrm{E}-4$ & Itgb2|Lbp|Trem2|Slc11a1|Fcer1g|Iglc2|Arhgap25|Fcgr3 \\
\hline Defense response & $3.16 \mathrm{E}-8$ & $\begin{array}{l}\text { Itgb2|Ccl8 } \mid \text { Lbp } \mid \text { Cyba|Ccl6|Ccl9|Evl|Ly86|Cd180|Trem2 } \\
\mid \text { H2-K1|Cfb|Slc11a1|Tfr2|Clec4a2|Cotl1|C1qc|Serpine1 } \\
\text { C1qb|H2-Ab1|H2-Aa|Ffar2|Lipa|Ptafr } \mid \text { Alox5ap } \mid \text { Fcer1g } \\
\text { Myo1f } \mid \text { Hfe } \mid \text { Lyz2 } \mid \text { Cd74|Cd37|Iglc2|Ccr5|Unc93b1|Fcgr3 }\end{array}$ \\
\hline $\begin{array}{l}\text { Regulation of } \\
\text { cytokine } \\
\text { production }\end{array}$ & $1.6 \mathrm{E}-5$ & $\begin{array}{l}\text { Lbp|Cyba|Dies1|Ankrd2|Slc11a1|Clec4a2|Nckap1l|Tspo } \\
\text { Serpine1|Inhbb|Cd300ld|Ffar2|Ptafr|Postn|Fcer1g|Hfe } \\
\text { AF251705|Cd74|Ccr5|Unc93b1|Fcgr3 }\end{array}$ \\
\hline $\begin{array}{l}\text { Inflammatory } \\
\text { response }\end{array}$ & $2.38 \mathrm{E}-5$ & $\begin{array}{l}\text { Itgb2|Ccl8 } \mid \text { Lbp } \mid \text { Cyba } \mid \text { Ccl6 } \mid \text { Ccl9|Ly86|Cd180|Slc11a1 } \\
\text { Tfr2|Ffar2|Lipa } \mid \text { Ptafr } \mid \text { Alox5ap } \mid \text { Fcer1g|Hfe } \mid \text { Ccr5|Fcgr3 }\end{array}$ \\
\hline $\begin{array}{l}\text { B cell mediated } \\
\text { immunity }\end{array}$ & $4.94 \mathrm{E}-5$ & C1qc|C1qb|H2-Ab1|Lilrb3|Fcer1g|Cd74|Iglc2|Fcgr3 \\
\hline Chemotaxis & 0.0015 & $\begin{array}{l}\text { Itgb2 } \mid \text { Ccl8 } \mid \text { Lbp } \mid \text { Ccl6 } \mid \text { Ccl9|Evl|Alcam } \mid \text { Nckap1l|Rac2 } \\
\text { Ffar2|Ptafr } \mid \text { Fcer1g } \mid \text { Ccr5|Fcgr3 }\end{array}$ \\
\hline
\end{tabular}

Table 4 KEGG pathways and processes with enriched immune-related genes found to be differentially expressed in sciatic nerves from SC-p $75^{\mathrm{NTR}}$-KO HFD mice but not in those from WT HFD animals. 


\begin{tabular}{|c|c|c|}
\hline $\begin{array}{l}\text { KEGG } \\
\text { Pathway }\end{array}$ & p-value & Enriched Genes \\
\hline Lysosome & $3.45 \mathrm{E}-5$ & Ctsb $\mid$ Ctsk $\mid$ Npc2|Ctsl|Gusb|Slc11a1|Man2b1|Lipa|Cd68|Laptm5 \\
\hline Phagosome & $8.1 \mathrm{E}-4$ & $\begin{array}{l}\text { Itgb2 } \mid \text { Cyba|Ctsl|H2-K1|H2-Ab1|H2-Aa| } \\
\text { H2-Eb1|Mrc2|Fcgr3 }\end{array}$ \\
\hline $\begin{array}{l}\text { Cholesterol } \\
\text { metabolism }\end{array}$ & 0.002 & Angptl4|Npc2|Tspo|Lipa|Pltp \\
\hline Peroxisome & 0.0025 & Acaa1b|Hsd17b4|Prdx5|Pex16|Acox1|Abcd2 \\
\hline $\begin{array}{l}\text { Cell adhesion } \\
\text { molecules } \\
\text { (CAMs) }\end{array}$ & 0.0092 & Itgb2|Alcam|H2-K1|H2-Ab1|H2-Aa|H2-Eb1|Selplg \\
\hline
\end{tabular}

Table 5 Differential enriched KEGG pathways in the SC-p75 ${ }^{\mathrm{NTR}}-\mathrm{KO}$ with HFD (non-immune related) versus SC-p75 ${ }^{\mathrm{NTR}}$-KO counterparts. These pathways were not found to be activated by HFD in WT mice. 


\begin{tabular}{|c|l|c|c|}
\hline Gene & \multicolumn{1}{|c|}{ Protein name } & Probability & Fold change \\
\hline Ctsb & Cathepsin B & 0.85 & 2.63 \\
\hline Ctsk & Cathepsin K & 0.81 & 2.08 \\
\hline Ctsl & Cathepsin L & 0.83 & 2.18 \\
\hline Ctss & Cathepsin S & 0.88 & 3.88 \\
\hline Npc2 & $\begin{array}{l}\text { Intracellular cholesterol } \\
\text { transporter 2 }\end{array}$ & 0.83 & 2.22 \\
\hline Gusb & Beta-Glucuronidase & 0.82 & 2.52 \\
\hline Slc11a1 & $\begin{array}{l}\text { Natural resistance-associated } \\
\text { macrophage protein 1 }\end{array}$ & 0.81 & 2.74 \\
\hline Man2b1 & Lysosomal alpha-mannosidase & 0.82 & 2.51 \\
\hline Lipa & Lysosomal acid lipase & 0.83 & 2.36 \\
\hline Cd68 & Macrosialin & 0.88 & 3.83 \\
\hline Laptm5 & $\begin{array}{l}\text { Lysosomal-associated } \\
\text { transmembrane protein 5 }\end{array}$ & 0.83 & 2.46 \\
\hline
\end{tabular}

Table 6 Enriched genes related to the Lysosome KEGG Pathway, upregulated only in nerves from SC-p75 ${ }^{\text {NTR }}$-KO mice with HFD, as compared with WT HFD. 


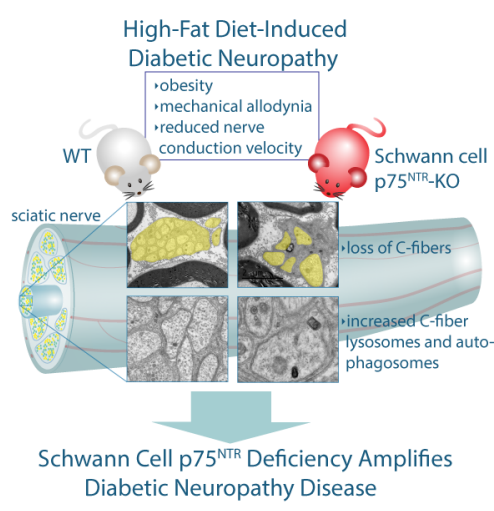

GLIA_23881_TOCI image.tif

This article is protected by copyright. All rights reserved. 